\title{
Weitere Erfahrungen über Hirnpunktionen bei Fällen von Hirntumoren und Epilepsie.
}

\author{
Von \\ Prof. Dr. Berthold Pfeifer, \\ Oberarzt der Klinik.
}

(Aus der Kgl. Universitätsklinik für Nerven- und Geisteskranke zu Halle a. S. [Prof. Anton].)

Mit 5 Textfiguren und 3 Tafeln.

(Eingegangen am 2. Mai 1911.)

Angesichts der zahlreichen und günstigen diagnostischen Erfolge, die ich selbst schon vor einer Reihe von Jahren mittels Hirnpunktion bei der Diagnose von Hirntumoren aufzuweisen hatte, ist die Zahl der Literaturbeiträge auf diesem speziellen Gebiete in der letzten Zeit eine auffällig geringe gewesen.

Die in den letzten Jahren über Hirnpunktionen publizierten Arbeiten beziehen sich in der Mehrzahl der Fälle auf die Diagnose flüssiger Substanzen. So berichtet Heyde $\mathbf{e}^{\mathbf{l}}$ ) über einen Fall von Hirnabsceß, der von Friedrich im hinteren Abschnitt des linken Stirnhirns nachgewiesen worden war. Säng er ${ }^{2}$ ) diagnostizierte mit Hilfe der Punktionsnadel ein subdurales Hämatom, A pelt ${ }^{3}$ ) zwei extradurale Hämatome.

Ziehen $\left.{ }^{4}\right)$ konnte mit Hilfe dieser Methode eine Cyste innerhalb der Hinterhauptschuppe und Finkelnburg) einen Fall von Hydrocephalus nachweisen. Namentlich hat Pol $\left(\mathrm{ack}^{6}\right.$ ) weitere diagnostische Erfolge mittels der Himpunktion durch Gewinnung flüssiger Substanzen erzielt, indem es ihm gelang, in einem Fall eine circumscripte Meningitis

1) Heyde, Zur bakteriologischen Ätiologie und Klinik des Hirnabscesses Deutsche med. Wochenschr. 1908, Nr. 51.

2) Sä nger, Ưber Areflexie der Cornea (Nutzen der Hirnpunktion bei traumatischer Hirnblutung). Neurol. Centralbl. 1910.

3) A pelt, Erwiderung auf die Arbeit von Pollack usw. Mitt. a. d. Grenzgeb. d. Med. u. Chir. 18, H. 4. 1908. Nr. 1.

4) Ziehen, Zur Differentiadiagnose des Kleinhirntumors. Med. Klin. 1909,

5) Finkelnburg, Beitrag zur therapeutischen Anwendung der Hirnpunktion beim chronischen Hydrocephalus. Münch. med. Wochenschr. 1910, Nr. 36.

b) Pollack, Weitere Beiträge zur Hirnpunktion. Mitt. a. d. Grenzgeb. d. Med. u. Chir. 18, H. l. 1907. 
serosa, in vier Fällen extradurale und intradurale Hämatome und in zwei Fällen Hirnabscesse nachzuweisen.

Uber positive diagnostische Resultate mittels Hirnpunktion bei Hirngeschwülsten berichtete Danielsen $n^{1}$ ) in zwei Fällen, während Reich $^{2}$ ) und Forster ${ }^{3}$ ) bei Besprechung klinischer Fehldiagnosen in Fällen von Hirntumoren es bedauerten, daß die Hirnpunktion nicht zur Sicherung der Diagnose mit herangezogen war.

In allerletzter Zeit sind sowohl von Willige und Landsbergen ${ }^{4}$ ) als auch von mir selbst ${ }^{5}$ ) Fälle mitgeteilt worden, bei welchen es gelang, mittels Hirnpunktion die histologische Diagnose von organischen Erkrankungen der Hirnrinde zu stellen.

Bei den beiden von mir veröffentlichten Fällen konnte durch die histologische Untersuchung der durch die Punktion gewonnenen Hirnrindenstückchen mit Sicherheit die Diagnose einer progressiven Paralyse gestellt und andere differentialdiagnostisch in Frage kommende Hirnerkrankungen, die eventuell einen operativen Eingriff erfordert hätten wie Gummi, Tumor, Cysticerkose ausgeschlossen werden.

Uber meine eigenen im Verlaufe der letzten Jahre bei weiteren Fällen von Hirntumoren mittels der Hirnpunktion erzielten Resultate habe ich bereits auf dem Congreß der British Medical Association in Birmingham im Juli 1911 ganz kurz berichtet $\left.{ }^{6}\right)$.

Im folgenden möchte ich nun die einzelnen Fälle ${ }^{7}$ ) in extenso mitteilen, einerseits zur näheren Illustrierung der bemerkenswerten diagnostischen Erfolge, welche in einer Reihe derselben mit Hilfe der Punktionsnadel gewonnen wurden, andererseits auch wegen der Beiträge zum Kapitel der Gefahren der Hirnpunktionen, die einige derselben liefern.

Wenn auch der diagnostische Wert der Hirnpunktion allgemein anerkannt ist, so herrscht doch bezüglich der Indikation zu ihrer Anwendung noch keineswegs völlige UUbereinstimmung. So ist z. B. Ziehen der Ansicht, daß noch viele Fälle gesammelt werden müßten, bis mit

1) Da nielse n, Hirnpunktionen. Berl. klin. Wochenschr. 1900, H. 4.

2) Reich, Demonstration über Hirngeschwülste usw. Neurol. Centralbl. 1910, Nr. 2.

3) Forster, Die Himpunktion. Berl. klin. Wochenschr. 1909, Nr. 7.

4) Willige und La ndsbergen, Histologische Diagnose diffuser Hirnerkrankungen durch Hirnpunktion. Münch. med. Wochenschr. 1912, Nr. 1.

5) Pfeifer, Zur histologischen Diagnose der progressiven Paralyse mittels Hirnpunktion. Münch. med. Wochenschr. 1912.

6) Pfeifer, Puncture of the Brain for Diagnostic purposes. Brit. med. Journ. September 1911.

7) Es handelt sich hierbei ausschließlich um Fälle, bei welchen die Himpunktion von mir selbst ausgeführt wurde. Über einige andere in Halle punktierte Kranke wird von anderer Seite berichtet werden. 
einiger Sicherheit Indikationen für die Probepunktion einerseits und die sofortige Trepanation andererseits aufgestellt werden könnten.

Jedenfalls ist es dringend wünschenswert, daß alle Fälle mit irgendwelchen nachteiligen Folgeerscheinungen der Hirnpunktion zur Veröffentlichung kommen, um über die mit der Hirnpunktion verbundenen Gefahren mehr und mehr Klarheit zu gewinnen und dieselben in späteren Fällen soweit als möglich zu vermeiden.

Die 36 Fälle, über welche ich im folgenden berichten möchte, lassen sich in fünf Gruppen einteilen.

Die erste Gruppe umfaßt 5 Patienten, welche auf Grund eines positiven Resultats der Hirnpunktion zur operativen Behandlung kamen, die zweite, ebenfalls 5 Patienten, bei welchen das Resultat der Hirnpunktion zwar auch ein positives war, eine operative Behandlung aber aus verschiedenen Gründen nicht stattfand, während das Punktionsresultat durch die Sektion bestätigt wurde.

Die dritte Gruppe enthält ausschließlich Fälle von Tumoren der hinteren Schädelgrube mit Sektionsbefund, bei welchen auf Grund des negativen Resultats der Himpunktion ein für die Operation zugänglicher Sitz der Geschwülste in den Kleinhirnhemisphären ausgeschlossen und deshalb ein operativer Eingriff nicht vorgenommen worden war.

In der vierten Gruppe ist kurz über Hirnpunktionen bei drei Epileptikern mit nachfolgender Trepanation $u_{n}$ d in der fünften schließlich über Punktionen bei einer Anzahl von Hirntumorverdächtigen berichtet, die aber nicht zur Operation bzw. Sektion kamen.

\section{Krankengeschichten der Fälle, welche auf Grund des positiven Resul- tats der Hirnpunktion operiert wurden.}

1. M. Heinrich, 45jähriger Arbeiter. Aufnahme 28. Juli 1909.

Anamnese: Vor 4 Wochen Schwindelanfall mit kurzdauernder Verwirrtheit. An den folgenden 14 Tagen noch 3 weitere Schwindelanfälle. Nach dem letzten Anfall Kopfschmerzen, Sprachstörungen, Ungeschicklichkeit des rechten Armes und Beines.

Status: Pupillenreaktion auf Licht rechts etwas träge. Rechte Pupille enger als linke. Partielle rechts. Hemianopsie. Temporaler Teil der Papille beiderseits etwas blaß, nasaler gerötet, reichlich vaskularisiert und etwas ödematös. Grenzen unscharf. Bei späterer Untersuchung deutliche Stauungspapille. Facialisinnervation rechts $<$ links. Zungenabweichung nach rechts. Motorische Apraxie beider Hände. Patellarreflexe rechts $>$ links.

Verlauf: Häufig Erbrechen und Kopfschmerzen an der linken Kopfseite; Schwindelanfälle. Erschwerte Wortfindung. Gegenstände werden erkannt, aber meist nicht oder paraphasisch benannt. Beim willkürlichen Sprechen häufig Paraphasien. Sprachverständnis nicht schwer beeinträchtigt. Nachsprechen gut. Lautlesen fast unmöglich. Leseverständnis erschwert. Spontanschreiben und Abschreiben aufgehoben.

Klinische Diagnose: Tumor des linken Schläfelappens.

Am 19. August 1909 Hirnpuntion am hinteren Teil des linken 
Schläfelappens. Es werden mehrere Kubikzentimeter einer gelblichroten, schleimigen Flüssigkeit mit mehreren Gewebspartikelchen aspiriert.

Mikroskopisch: Sehr zellreiches Gewebe. Die Zellen haben vielgestaltige große Kerne. Das Protoplasma zeigt deutliche Verästelungen.

Diagnose: Gliom.

Am Tage nach der Punktion ist das Spontansprechen auffallend besser, ebenso die Wortfindung.

Am 23. August in die chirurgische Klinik verlegt.

Am 24. August O peration (Prof. Haasler). Nach Eröffnung der Schädelkapsel oberhalb des linken Ohrs zeigt sich zunächst, daß bei der Schädelbohrung der hintere Ast der Art. men. med. völlig durchbohrt wurde. Die Gefäßenden sind retrahiert und thrombosiert. Keine Spur von Blut oder Blutresten. Der linke Schläfelappen zeigt graurötliches Aussehcn. Beim Eingehen mit der Pinzette entleert sich gelblichbraune Flüssigkeit. Dieselbe stammt aus einer walnußgroßen Höhle, deren Wandung aus graurötlichem Gewebe besteht. Eine vö̈lige Ausschälung des Tumors ist wegen der diffusen Grenzen nicht möglich. Ein Teil desselben wird entfernt

Mikroskopische Untersuchung ergibt: Zellreiches Gliom mit deutlichen Spinnenzellen.

An den folgenden Tagen erhebliche Besserung des subjektiven Befindens. Keine Kopfschmerzen, kein Schwindel, kein Erbrechen, Geläufiges Sprechen. Bessere Beweglichkeit der Extremitäten, keine Apraxie, keine Erschwerung der Wortfindung. Nach mehreren Wochen wieder zunehmende Verschlechterung. Schließlich totale Aphasie.

Exitus letalis am 18. November 1909.

Sektion am 19. November 1909. An der linken Schläfegegend Trepanationsnarbe mit Defekt des Knochens. Innenfläche der Dura trockener als normal. Gyri abgeplattet, besonders an der linken Parietalgegend. Der vordere Pol des linken Schläfelappens und die darüber befindliche Dura ist gegen die Operationsnarbe hin fest bindegewebig fixiert, so daß Dura und linker Temporalmuskel verwachsen sind. Die linke Fossa Sylvii ist an ihrem vorderen Teil durch einen im linken Schläfelappen sitzenden Tumor überbrückt, so daß dieser mit einem kaum haselnußgroßen Anteil in die graue Substanz der linken unteren Stirnwinddung hineingewuchert ist.

Bei Frontalschnitten konstatiert man einen den ganzen linken Schläfelappen einnehmenden, bis dicht an die Fossa Sylvii heranreichenden und weit in das Marklager hinein sich erstreckenden Tumor, der ein eigentümlich buntes Bild bietet, indem auf meist gelbem Grunde sich teils sulzig cystische Partien abheben, teils die Substanz stärker durchblutet ist. In einer circumscripten, kaum haselnu Bgroßen Partie hat der Tumor pechschwarze Farbe angenommen. Die Abgrenzung gegen die normale Hirnsubstanz ist sehr undeutlich. Im Gebiet der Operationsnarbe hat die Tumormasse auf die Hirnhäute übergegriffen. Der rechte Seitenventrikel ist stark dilatiert.

Diagnose post mortem: Gliom des linken Temporallappens. Hydrocephalus internus.

$$
\text { Epikrise: }
$$

Die allmählich aufgetretenen Allgemeinsymptome, wie Schwindelanfälle, Kopfschmerzen, Erbrechen und Stauungspapille sprachen für das Vorhandensein eines Tumors.

Die Lokalsymptome wiesen in der Hauptsache auf die linke Großhirnhemisphäre hin. Wegen der ausgesprochen sensorisch-aphasischen Erscheinungen war eine Lokalisation der Geschwulst im linken Schläfelappen am wahrscheinlichsten, 
wobei wegen der rechtsseitigen Hemiparese mit Betroffensein des Facialis- und Hypoglossusgebietes und wegen der rechtsseitigen Hemianopsie eine erhebliche Ausdehnung des Tumors nach dem tiefen Marklager hin, bzw. Nachbarschaftswirkung auf dasselbe anzunehmen war.

Die Erweiterung der linken Pupille konnte als Ausfallssymptom von seiten des linken Oculomotorius durch Druckwirkung des Tumors auf die Schädelbasis (K napp) bedingt sein.

Durch einmalige Hirn punktion im Bereich des hinteren Abschnitts des linken Schläfelappens wurde ein teilweise cystisch verändertes Glio m festgestellt. Nach der Punktion trat zunächst eine Besserung der sensorischaphasischen Störungen ein. Die Diagnose wurde durch die später vorgenommene Operation bestätigt. Eine Radikaloperation war allerdings wegen der diffusen Beschaffenheit des Tumors nicht möglich. Die Operation hatte aber doch eine, wenn auch vorübergehende wesentliche Besserung der Allgemeinsymptome und der sensorisch-aphasischen Störungen zur Folge. Späterhin steigerten sich die letzteren allerdings wieder bis zu totaler Aphasie.

Etwa ein Vierteljahr nach der Operation erfolgte der Exitus letalis. Die Sektion ergab ein weit ausgedehntes diffus begrenztes inoperables Gliom des linken Schläfelap pens, von dem eine etwa haselnußgroße Partie in den Fuß der dritten Stirnwindung hineinragte.

2. P., Albert, 36 jähriger Schlosser aus Halle. Aufnahme: 20. September 1909.

Anamnese: Keine erbliche Belastung. Vor 2 Jahren Kopfverletzung, sei immer leicht aufgeregt gewesen, seit einigen Wochen Kopfschmerzen, besonders links. Erbrechen, Stumpfheit, Schlafsucht.

Status: Pupillen mydriatisch, ungleich weit. Reaktion auf Licht auffallend träge. An beiden Augen Stauungspapille, links > rechts, mit kleinen Hämorrhagien. Unruhe der Bulbi. Aphasische Störungen, besonders starke Behinderung des Nachsprechens, während das Sprachverständnis ziemlich gut erhalten ist. Anfangs keine erhebliche Störung der Spontansprache. Später auch sensorisch-aphasische Sprachstörungen, Paraphasien beim Sprechen, Lesen und Schreiben; aber immer besonders hochgradige Störung des Nachsprechens.

Klinische Diagnose: Tumor des linken Schläfelappens.

Am 2. Oktober 1909 Pu nktion etwa über de m mittleren Teil der linken ersten Schläfewindung. Es werden einige Gewebspartikelchen von glasigdurchsichtigem Aussehen aspiriert.

Mikroskopisch: Ausges prochenes Gliom.

28. Oktober Verlegung in die chirurgische Klinik.

Operation 5. November 1909 (Geheimrat v. Bramann). Nach Zurückklappen eines Hautperiostknochenlappens über dem linken Ohr zeigt sich die Dura weißlich, stark gespannt. Keine sichtbare, wohl aber fühlbare Pulsation. Nach Umschneidung der Dura wölbt sich das Gehirn stark vor. Aus demselben ergießt sich plötzlich klare, bernsteingelbe Flüssigkeit. Beim Eingehen daselbst mit dem Finger kommt man in eine etwa walnußgroße Höhle, deren Wandung von einer weichlichen Tumormasse gebildet wird. Auskratzen der Tumormassen, teils stumpf, teils mit dem scharfen Löffel, so daß schließlich eine enteneigroße Höhle resultiert. Mäßige Blutung. Tamponade locker mit Jodoformgazedrains. Naht der Dura mit Seide.

Nach der Operation Puls zeitweise klein, Pupillen beiderseits eng.

Mikroskopischer Befund der Tu morstücke: Zellreiches Gewebe. Die Zellen haben fast durchweg den ausgesprochenen Charakter der Spinnenzellen.

Diagnose: Gliom.

Weiterer Verlauf: Bewegungen mit der rechten Hand schwach und un- 
sicher. Die Sprache ist wesentlich schlechter geworden. Patient versteht nichts und spricht völlig unverständlich. Nach etwa 5 Tagen langsam zunehmender Temperaturanstieg. Einige Tage später starke Durchblutung des Verbandes. Puls bis 140. Die Blutung rührte von der anscheinend durch die Knochenplatte verlegten Art. temporalis her. Unterbindung. Entfernung des Knochenstückes. Aus der Hirnhöhle entleert sich dicker Eiter. Patient macht häufig Schmatzbewegungen. Zunehmende Pulsverschlechterung.

Exitus letalis 1. Dezember 1909.

Sektion am 2. Dezember 1909. In der linken Schläfegegend eine lappenförmige Operationswunde, aus deren hinterem Wandwinkel Hirnsubstanz vorquillt. Ränder der vorgequollenen Hirnsubstanz eitrig belegt. Im Bereich der Zentralwindungen links sind die Suberachnoidealmaschen mit grünlich-gelbem Eiter belegt. An der Hirnbasis ist besonders die Gegend der basalen Cisternen sowie der weichen Hirnhäute über dem Kleinhirn eitrig infiltriert. Bei Eröffnung des linken Seitenventrikels trifft man auf den in den Ventrikel durchgebrochenen Tumor. In den Seitenventrikeln, sowie im dritten und vierten Ventrikel Eiter. Die ganze Hirnsubstanz stark ödematös, blaß.

Der Tumor nimmt den hinteren Teil des linken Schläfenlappens, den vorderen des linken Occipitallappens ein und reicht in die Tiefe bis zum Ventrikel. Er ist mit roten und gelben, teils eitrig eingeschmolzenen Partien durchsetzt und unscharf gegen die normale Hirnsubstanz abgegrenzt.

Diagnose post mortem: Meningitis purulenta diffusa. Pyocephalus internus. Zerfallendes Gliom des linken Temporo-Parietallappens.

\section{Epikrise:}

Die Allgemeinsymptome eines Hirntumors waren in diesem Fall stark ausgesprochen und hatten sich im Verlauf einiger Wochen rasch entwickelt. Die sensorisch-aphasischen Störungen wiesen auch hier auf den linken Schläfelappen hin und zwar konnte man daran denken, daß bei der anfänglich im Vordergrund stehenden Störung des Nachsprechens bei relativ gut erhaltenem Sprachverständnis, wenigstens nach der Wernickeschen Anschauung, die allerdings jetzt von Lie pmann und anderen angefochten wird, mehr die Inselgegend bzw. weiter nach vorn gelegene Teile des linken Schläfelappens betroffen seien.

Durch einmalige Hirnpunktion am mittleren Teil der ersten linken Schläfewindung wurde ein Gliom festgestellt. Durch die nachfolgende Operation wurde die Diagnose bestätigt, doch zeigte sich, daß auch dieser Tumor infolge seiner Größe und diffusen Beschaffenheit nicht radikal zu operieren war. Die Eröffnung einer innerhalb des Tumors befindlichen Cyste und die teilweise Entfernung des Tumors bewirkten keine nennenswerte Besserung des Zustandes.

Der Kranke starb bereits nach Ablauf eines Monats nach der Operation an Pyocephalus internus und eitriger Meningitis, nachdem eine starke Durchblutung des Verbandes einige Zeit vorher vorausgegangen war.

3. U., Max, 42jähriger Arbeiter aus Nietleben. Aufnahme: 2. Februar 1910.

Anam nese: Sommer 1909 Kopfschmerzen. Seit Anfang 1910 Ohrensausen, besonders rechts, und Schwindel mit Scheinbewegungen der Gegenstände im Sinne des Uhrzeigers. Mehrfach Erbrechen. $\mathrm{Ab}$ und zu Kribbeln im rechten Bein; unsicherer Gang.

Status: Sprache verlangsamt, monoton. Pupillen ungleich, rechte etwas weiter als linke. Lichtreaktion rechts < links. Beiderseits Stauungspapille. Sehschärfe rechts auf $1 / 2$, links auf $1 / 4$ herabgesetzt. Schwerhörigkeit. Flüstersprache rechts auf $2 \mathrm{~m}$, links auf $3 \mathrm{~m}$ gehört. Rechtsseitige homonyme Hemianopsie. 
Leichtes Intentionszittern rechts. Einzelbewegungen der Finger rechts etwas ungeschickter als links. Beim Hochheben der Beine etwas Zittern; Patellar- und Achillessehnenreflexe beiderseits gesteigert. Beiderseits Patellar- und Fußklonus von wechselnder Intensität. Lagegefühlsstörungen geringen Grades an den Zehen. Keine aphasischen oder apraktischen Störungen, keine Alexie; dagegen ausgesprochene Agraphie, sowohl für Spontan- als für Diktat- und Abschreiben.

Klinische Diagnose: Tumor des linken Occipitallappens. (Aber a uch Erscheinungen von seiten der hinteren Schädelgrube.)

Am 22. Februar 1910 Balkenstich zur Druckentlastung.

Am 5. März 1910 Hirnpunktionen.

1. A m linken Occipitalla p pen. Dura in $2 \mathrm{~cm}$ Tiefe durchstochen. Punktion bis $3 \mathrm{~cm}$ Hirntiefe. Die Aspiration ergibt eine große Menge von grauen, glasig aussehenden Gewebsmassen.

2. Am hinteren Teil des linken Parietallappens.

Resultat der Punktion das gleiche.

Mikroskopisch: In beiden Fällen Züge von dicht aneinander liegenden, meist spindeligen Zellen, die an einzelnen Stellen nestförmige Anordnung zeigen.

Diagnose: Endotheliom.

Am 9. März 1910 Operation (Geheimrat v. Bramann). Die Dura in der Umgebung der Punktionsstellen bräunlich verfärbt. Keinerlei Entzündungserscheinungen daselbst. Unter der Hirnoberfläche fühlt man einen apfelgroßen Tumor, der gegen das Hirn scharf abgegrenzt ist. Derselbe wird stumpf losgelöst. Am Tentorium sitzt er fest. Nach Entfernung des Tumors haftet an der Ansatzstelle am Tentorium noch ein Zapfen. Operation wegen starker Blutung unterbrochen. 13. März Excision eines Stückes des Tentoriums mit der Geschwulstansatzstelle.

Die mikroskopische Untersuchung des Tumors ergibt die Diagnose: Endothelioma psammomatodes.

Infolge Eröffnung des Ventrikels reichlicher Erguß von Liquor aus der Wunde.

An den folgenden Tagen Temperatursteigerungen, Schüttelfröste. Häufigen Verbandswechsel wegen Durchnässung des Verbandes mit Liquor. Außer der Agraphie sind jetzt auch sensorisch-aphasische, agnostische und apraktische Störungen aufgetreten.

Am 13. März Exitus letalis.

Am 14. März 1910 Sektion.

Frische Trepanationswunde über dem linken Occipitalhirn. Ältere Punktionswunde an der rechten Präzentralgegend. (Balkenstich.) An der Hirnoberfläche die Zeichen gesteigerten Hirndrucks.

Leptomeningitis purulentabasalis et ventricularis praecique dextra. Operativer Defekt am lateralen und basalen Anteil des linken Occipitallap pens. Brandschorf im linken Tentorium. Eitrige Beläge in der Dura der hinteren Schädelgrube, sowie über dem linken Felsenbein. Anämie und Ödem des Gehirns. Erweichung in der Umgebung der Operationswunde.

\section{Epikrise:}

Als Allgemeinsymptome kommen in diesem Falle Kopfschmerzen, Ohrensausen, Schwindel, Erbrechen, Stauungspapille, sowie Herabsetzung des Seh- und Hörvermögens in Frage.

Von den Lokalsymptomen wiesen die rechtsseitige Hemianopsie in Verbindung mit der isolierten Agraphie auf den linken Occipitallappen hin. Das Kribbeln im rechten Bein war bei Annahme dieser Lokalisation als Reizwirkung auf den benachbarten linken Parietallappen aufzufassen. 
Außerdem sprachen aber auch eine Reihe von Symptomen für ein Betroffensein des Kleinhirns, wie der unsichere Gang, die Adiodakokinese, das Intentionszittern und die spastische Parese beider Beine.

Zwei Hirnpunktionen am linken Occipitallappen und am hinteren Teil des linken Parietallappens ergaben an beiden Stellen das Vorhandensein eines Endothelioms, entschieden also die klinisch noch zweifelhafte Lokaldiagnose im Sinne einer Lokalisation der Geschwulst im Bereich des Occipito-Parietallappens.

Bei der Operation wurde am Occipito-Parietallappen ein bis nahe a n die Oberfläche reichender Tumor gefunden. Bei stumpfer Loslösung der etwa apfelgroßen, gegen das Gehirn gut abgegrenzten Geschwulst, stellte sich heraus, daß dieselbe vom Tentorium ausgegangen war. Dieselbe hatte also bei ihrem Wachstum nach vorn - oben durch Druck die Erscheinungen von seiten des linken Hinterhaupts- und Scheitellappens und andererseits durch Druck nach hinten - unten auch Kleinhirnsymptome verursacht. Hätte man vor der Operation gewußt, daß die Ausgangsstelle des Tumors das Tentorium war, so hätte man die Trepanationsöffnung weiter hinten, direkt über den Sinus transversus anlegen müssen. Der Tumor hätte dann, ohne daß eine Verletzung des Gehirns stattzufinden brauchte, entfernt werden können. Dafür war aber leider vor der Operation kein Anhaltspunkt zu gewinnen. Die durch die Hirnpunktion festgestellte histologische Beschaffenheit der Geschwulst machte es zwar, da es sich um ein Endotheliom handelte, wahrscheinlich, daß dieselbe von der Dura mater ausgegangen war, jedoch war zu vermuten, daß sie ihren Ursprung von der lateralen Fläche des linken Occipito-Parietallappens entsprechenden Dura genommen hatte. So wurde die radikale Entfernung des Tumors zu einem außerordentlich schweren Eingriff, da derselbe durch den hinteren Abschnitt des linken Großhirnhemisphäre hindurch mit Eröffnung des Hinterhorns herausgeholt wurde. Infolge der Ventrikeleröffnung war der Verband nach der Operation stets von dem abfließenden Liquor durchnäßt. Daß in solchen Fällen eine Wundinfektion schwer zu vermeiden ist, ist bekannt. Es trat denn auch schon nach einigen Tagen Schüttelfrost auf. Zu der reinen Agraphie gesellten sich sensorisch-aphasische, agnostische und apraktische Störungen.

Vier Tage nach der Operation erfolgte der Exitus letalis, infolge von eitriger Meningitis.

4. R., Marie, 39jährige Frau aus Alterode. Aufnahme: am 11. Januar 1910.

Anam nese: $1908 \mathrm{im}$ Ansehluß an Geburt eines Kindes heftige Kopfschmerzen besonders an der Stirn. Bisweilen Flimmern vor den Augen. Bewußtloses Zusammenstürzen. Schlechteres Sehen. Zeitweise Erbrechen. Nach vorübergehender Besserung im Oktober 1909 wieder Zunahme der Beschwerden. Häufigeres Erbrechen. Sehr starke Kopfschmerzen. Zusammenstürzen ohne Krämpfe mit nachfolgender Bewußtlosigkeit. Während solcher Anfälle Herabsinken des rechten Augenlids. Seit 4 Wochen vor Aufnahme Erblindung.

Status: Beide Bulbi prominent. Pupillenreaktion auf Licht fehlt. Auf Naheeinstellung prompte Verengerung. Nystagmusartige Zuckungen in linker und rechter Endstellung. Leichte rechtsseitige Trochlearisparese. Rechts Spur von Lichtschein, links Amaurose. Beiderseits hochgradige Stauungspapille. Geruch beiderseits herabgesetzt. Rechtsseitige Facialisparese am oberen und unteren Ast. Hirnnerven sonst ohne Besonderheiten. Leichte Parese des linken Armes und Beines. Patellarreflexe links $>$ rechts. Links Fußklonus. Babinski und Oppenheim links deutlich. Gang breitspurig, unsicher.

Verlauf: Viel Kopfschmerzen. Häufig Anfälle von Bewußtlosigkeit. Am 
24. März Balkenstich. $10 \mathrm{ccm}$ Liquor entfernt. Am Boden des Ventrikels wird eine Resistenz gefühlt.

Nachher Kopfschmerzen geringer. Anfälle fortdauernd. Später leichte Ataxie des linken Armes und Beines. Auch deutliche Lagegefühlsstörung an den Fingern und Zehen links. Im Anfall Ptosis rechts, forcierte Augendrehung nach rechts. Linker Arm wird erhoben und zittert. Fällt dann schlaff herab. Tricepsreflex links $>$ rechts. Leichter Intentionstremor links.

Klinische Diagnose: Tumor der rechten Hemis phäre, wahrscheinlich im Schläfenlappen, ev. an der Schädelbasis.

Am 24. Juni 1910 Hirnpunktion am rechten Schläfenlappen. Es werden etwa $10 \mathrm{ccm}$ Ventrikelflüssigkeit aspiriert. Anfangs leicht hämorrhagisch, später klar. In derselben schwimmen zahlreiche feine, weiße Gewebsstückchen oben auf, während zwei zylinderförmige Stückchen untersinken. (Punktion gut vertragen.)

Mikroskopisch sind die letzteren normal: die ersteren bestehen aus kernlosen, lamellös angeordneten fasrigen Geweben.

Diagnose: Cholesteatom des rechten Schläfelappens. (Geheimrat Ebert). In der Nacht der nach Punktion stärkeres Erbrechen. Patient gibt an, besser zu sehen. Objektiv keine Veränderung nachweisbar. Keine Hörstörung.

7. Juli O peration. (Geheimrat v. Bra mann.) Bildung eines Hautknochenlappens über dem rechten Ohr. Gehirn sehr gespannt und blutreich. Punktion des rechten Unterhorns und Entleerung von $15 \mathrm{ccm}$ klaren Liquors. Hierauf geringere Spannung. In der Tiefe des rechten Schläfenlappens ist eine undeutliche Resistenz fühlbar. Die zweite Schläfewindung wird geöffnet. Der vordringende Finger fühlt in der Tiefe einen harten Tumor. Derselbe wird in Form von bröckeligen, weiß glänzenden Massen, die sich gegen das gesunde Gehirn gut abgrenzen, mit dem scharfen Löffel herausbefördert.

Nach Entfernung der Tumormassen (etwa $100 \mathrm{~g}$ ) bleibt eine apfelgroße Höhle, welche nach hinten bis in den Occipitallappen, nach medialwärts bis nahe an die Falx cerebri reicht.

Drain im hinteren Wundwinkel. Naht der Dura. Hautknochenlappen eingelegt und bis auf die Drainstelle vernäht.

Puls ist relativ gut geblieben.

Mikroskopische Untersuchung der Tumormassen ergibt: Cholesteatom. Patient ist abends völlig klar, doch häufiges Erbrechen und sehr starkes Druckgefühl. Auch an den folgenden Tagen noch viel Durst und oft Erbrechen.

Am 22. Juli wird conjugierte Augenabweichung nach rechts und Schwäche und Anästhesie am linken Arm und Bein festgestellt. Leichte Schwäche des linken Facialis. Kopfwendung nach links schwächer als nach rechts.

In den folgenden Wochen dauernd relatives Wohlbefinden. Wunde bis auf die Drainstelle größtenteils überhäutet. Aus dem Drainrohr entleeren sich zeitweise kleine nekrotische Partikelchen. Anfangs September wieder Temperatursteigerung. Prominenz der Schädelwunde. Stirnkopfschmerzen. Nochmalige Auskratzung der Höhle von der Drainöffnung aus. Temperaturabfall.

Eine Woche später wieder Temperatursteigerung, Erbrechen, Kopfschmerzen.

Am 10. September 1910 Exitus letalis.

Sektionsbefund: Oberhalb des rechten Ohrs eine $11 \mathrm{~cm}$ lange, teilweise vernarbte, im hinteren Abschnitt offene Operationswunde, aus der grünlichgelbe Eitermasse $n$ hervorquellen. Dura stark gespannt mit der Hirnoberfläche verwachsen. Weiche Hirnhäute an der Konvexität getrübt, injiziert, an der Basis gelbgrün, sulzig infiltriert. In der rechten Schläfengr ube gelbgrüner Eiter. 
Auf einem Frontalschnitt durch den Scheitellappen zeigt sich, daß eine Absce B. höhle sich durch den ganzen rechten Schläfelappen bis in den Pol des Hinterhauptlap penserstreckt, die medianwärts in den Ventrikel durchgebrochen ist.

\section{Epikrise:}

Die Diagnose eines Hirntumors war auf Grund der progressiv entstandenen allgemeinen Hirndrucksymptome, wie Kopfschmerzen, Erbrechen, Synkopeanfälle, Erblindung durch Opticus-Atrophie infolge von Stauungspapille mit Sicherheit zu stellen.

Die Lokalsymptome waren zunächst nicht leicht zu beurteilen. Die ziemlich rasch eingetretene Erblindung und die mehrfach beobachteten Anfälle von plötzlichem Zusammenstürzen ließen zunächst an einen Tumor der hinteren Schädelgrube denken. Jedoch fehlten sonstige eigentliche Kleinhirnsymptome völlig. Die rechtsseitige Trochlearisparese und die basalen Charakter tragende rechtsseitige Facialisparese sprachen für einen basalen, oder wenigstens mit Druck auf die Schädelbasis einhergehenden Prozeß der rechten Hemisphäre. Die bei den Synkopeanfällen mehrfach beobachtete rechtsseitige Ptosis ließ besonders an eine auf die Schädelbasis drückende Geschwulst des rechten Schläfelappens denken. Die linksseitige Hemiparese, Hemiataxie und Lagegefühlsstörung konnten in diesem Falle als Nachbarschaftssymptome gedeutet werden. Jedoch war auch eine Lokalisation des Tumors in der rechten motorischen Region oder im rechten Scheitellappen nicht völlig auszuschließen.

Durch eine Hirnpunktion am rechten Schläfelappen wurde ein Cholesteatom festgestellt. Die Diagnose wurde durch die bald darauf vorgenommene Operation bestätigt. Die Cholesteatommassen, die etwa $100 \mathrm{~g}$ betrugen, wurden entfernt. Späterhin trat eine eitrige Meningitis ein. Der Tod erfolgte etwa 2 Monate nach der Operation. 1910.

5. A., Franz, 30 jähriger Bergmann, Wernerode. Aufnahme: 17. September

Anamnese: Seit Februar 1910 heftige Schmerzen über der rechten StirnScheitelbeingrenze; Störungen des Kauens, häufig U̇belkeit, ohne daß aber Erbrechen eintrat; kein eigentlicher Schwindel, aber Unsicherheit beim Treppensteigen; Abnahme des Sehvermögens seit zwei Monaten, zuweilen Doppelsehen; in letzter Zeit auch Abnahme des Gehörs. In der rechten Gesichtshälfte manchmal Kribbeln.

Status: Klopfschall über der rechten Stirnschläfenbeingegend heller als links. Der Kiefer weicht beim Öffnen des Mundes nach rechts ab. Hyposmie rechts. Beiderseits starke Stauungspapille. In der Umgebung der linken Papille kleine weißglänzende Herdchen. Das rechte Auge erreicht beim Blick nach rechts die Endstellung nicht ganz. Die Innervation des Mundfacialis setzt rechts prompter ein als links. Mundwinkel hängt beim Zähnezeigen etwas herunter. Sprache etwas verlangsamt. Beim Kopfschütteln Sausen im rechten Ohr; Pulsverlangsamung ( 64 pro Minute). Beim Finger - Nasen -Versuch links kurz vor dem Ziel etwas Zittern, ebenso beim Knie-Hacken-Versuch.

Klinische Diagnose: Tumor am hinteren Teil des rechten Stirnhirns bzw. am rechten Schläfenlappen.

Am 22. September 1910 Hirnpunktion:

1. Am hinteren Teil des rechten Stirnhirns in der Höhe zwischen Facialis und Armregion; es wird anscheinend normales Gewebe aspiriert.

2. Am rechten Schläfenlappen: Die Schuppe des rechten Schläfenbeines erscheint auffallend verdickt. Beim Einstechen der Punktionsnadel ungewöhnlich 
starker Widerstand. Es wird eine reichliche Menge pathologisch aussehendes Gewebe gewonnen.

Mikroskopischer Befund: Punktat des Stirnhirns normal. Das Gewebe aus dem rechten Schläfenlappen besteht aus zahlreichen dicht nebeneinander liegenden, sehr großen Zellen, die meist mehrere Kerne enthalten.

Diagnose: Endotheliom des rechten Schläfenlappens.

Punktion wurde gut vertragen.

Am 23. September 1910 Verlegung nach der chirurgischen Klinik.

Am 26. September 1910 Operation (Geheimrat v. Bramann). Bildung eines Weichteil-Knochenlappens über dem rechten Ohr mit der Punktionsöffnung am rechten Schläfenlappen als Mittelpunkt. Durch die prall gespannte Dura fühlt man derbe, knotige und flächenförmige Verhärtungen.

Nach Öffnung der Dura quillt sofort graurötliche Tumormasse hervor. Nach oben und hinten ist die Grenze des Tumors palpabel, dagegen nicht nach vorn und basalwärts trotz Erweiterung der Trepanationsöffnung. Die Dura ist von dem Tumor in großer Ausdehnung mit ergriffen. Beim Abziehen bleiben Tumorteilchen an ihr haften. Aber auch der Knochen erscheint an mehreren Stellen nicht ganz einwandfrei. Einige Tumorstïckchen werden entfernt. Radikaloperation ist wegen der großen Ausdehnung nicht möglich.

Mikroskopische Diagnose: Großzelliges Endotheliom.

Weiterer Verlauf: Nach der Operation Lähmung des linken Armes und Schwäche des linken Beines. Patient bleibt fieberfrei. In den folgenden Wochen sehr wenig Allgemeinerscheinungen. Patient gibt an, links besser zu sehen. Meist gute Stimmung. Geringer Prolaps an der Trepanationsstelle. Pat. war später bei gutem subjektiven Befinden dreimal teils in Behandlung der Nervenklinik, teils zu Hause. Der objektive Befund, bestehend in einer spastischen Parese der linken Extremitäten mit Herabsetzung der Sensibilität, linksseitiger Hemianopsie und mäßiger Opticusatrophie ohne Stauungserscheinungen, blieb im wesentlichen bis zu seiner letzten Entlassung am 25. Juli 1911, also 10 Monate nach Operation, im wesentlichen stationär. Nur eine allmähliche Zunahme der Hirnhernie zeigte, daß der Tumor weiter wuchs.

\section{Epikrise:}

Es bestanden etwa seit einem halben Jahr zweifellose Allgemeinsymptome eines Hirntumors, wie Kopfschmerzen, Übelkeit, Sehstörung infolge von Stauungspapille, sowie Pulsverlangsamung. Auch die Hörschwäche konnte als Allgemeinsymptom infolge von Staungslabyrinth aufgefaßt werden.

Die Lokalsymptome wiesen wieder wie bei dem vorigen Falle besonders auf die rechte mittlere Schädelgrube hin. Die Reizerscheinungen im Gebiet des sensiblen, die Ausfallserscheinungen von seiten des motorischen rechten Trigeminus und die rechtsseitige Abducensschwäche konnten durch Druck vom rechten Schläfenlappen aus, die rechtsseitige Hyposmie aber auch durch Druckwirkung vom hinteren Teil des rechten Stirnhirns bedingt sein. Auch die leichte linksseitige Facialisparese von cerebralem Charakter konnte durch Nachbarschaftswirkung auf den unteren Teil der motorischen Region sowohl vom hinteren Teil des rechten Stirmhirns, als auch vom rechten Schläfenlappen aus hervorgerufen sein. Außerdem entsprach auch die Aufhellung des Kopfschalles der rechten Stirn-Schläfegegend.

Zwei Hirnpunktionen, von welchen die eine etwa am hinteren Teil der rechten zweiten Stirnwindung, die andere am rechten Schläfenlappen gemacht wurden, ergaben ein Endotheliom des rechten Schläfenlappens, während am rechten Stirnhirn normaler Befund erhoben wurde.

Bei der am folgenden Tage vorgenommenen $O$ peration fand sich ein derbes großes Endotheliom des rechten Schläfenlappens, das sich aber auch 
noch in den basalen Anteil des rechten Stirnhirns hineinerstreckte. Die weiter dorsalwärts vorgenommene Punktion am hinteren Teil des rechten Stirnhirns hatte demnach den nur ventral vom Ventrikel lokalisierten Tumor nicht erreicht. Da eine Radikaloperation der Geschwulst wegen ihrer großen Ausdehnung nicht möglich war, mußte man sich mit einer teilweisen Entfernung derselben begnügen. Die histologische Diagnose des Punktats wurde durch die Untersuchung des exstirpierten Tumorteiles bestätigt.

Nach der Operation trat zwar eine leichte linksseitige Hemiparese mit Herabsetzung der Sensibilität und Hemianopsie ein, jedoch besserten sich die allgemeinen Hirndrucksymptome sehr erheblich. Der Zustand blieb dann bis zur Entlassung des Kranken, 10 Monate nach der Operation, stationär.

\section{Zusammenfassung:}

Bei den ausführlich erörterten fünf Fällen dieser ersten Gruppe, welche nach Hirnpunktion zur Operation kamen, ist es also jedesmal gelungen, mittels der Punktionsnadel eine genaue Lokal- und Artdiagnose eines Hirntumors zu stellen. Dabei wurde in zwei Fällen eine richtige klinische Diagnose durch die Hirnpunktion bestätigt, in drei Fällen über eine zweifelhafte Sicherheit gewonnen.

Die klinische Diagnose war in zwei Fällen von linksseitigen Schläfelappentumoren auf Grund des eindeutigen und deutlich ausgesprochenen Symptoms einer sensorischen Aphasie richtig gestellt worden; dagegen war sie in zwei Fällen von rechtsseitigen Schläfelappentumoren und bei einem vom Tentorium ausgegangenen Tumor, welcher sowohl occipitoparietale als Kleinhirnsymptome machte, zweifelhaft gewesen. Bei dem letzteren Fall hätte sich vielleicht durch wiederholte Punktionen zur Feststellzng der Tiefe des Sitzes der Geschwulst noch genauer ermitteln lassen, daß das Endotheliom nicht von der oberflächlichen Dura, sondern vom Tentorium ausgegangen war.

In allen diesen Fällen wurde die auf Grund der Himpunktion gestellte Lokal- und Artdiagnose des Hirntumors durch die nachfolgende Operation bestätigt.

Was die Artdiagnose angeht, so handelte es sich zweimal um Gliome, zweimal um Endotheliome und einmal um ein Cholesteatom. Die letztere Diagnose ist in diesem Falle zum erstenmal mittels Hirnpunktion gelungen.

In dem ersten Fall wurde zugleich der Nachweis geliefert, daß der Tumor teilweise im Inneren cystisch degeneriert war.

Unter diesen fünf Fällen von Hirntumoren war leider eine radikale Entfernung der Tumoren nur in zwei Fällen möglich, nämlich in Fall 3, wobei es sich um ein gut abgegrenztes, vom Tentorium ausgegangenes Endotheliom handelte und in Fall 4, in welchem ein Cholesteatom vorlag. Leider war aber in beiden Fällen zur Entfernung der Tumoren eine weitgehende Eröffnung der Hirnventrikel erforderlich, eine bekanntlich prognostisch wegen der großen Infektionsgefahr außerordent. 
lich ungünstige Komplikation, welche auch in diesen beiden Fällen den Exitus letalis infolge von eitriger Meningitis im Gefolge hatte und zwar in dem ersteren schon nach vier Tagen, in dem letzteren nach zwei Monaten.

Bei den übrigen drei Fällen konnten die Tumoren infolge ihrer großen Ausdehnung und diffusen Begrenzung nicht total exstirpiert werden. Bei einem derselben, Fall 2, bei welchem es sich um ein sehr großes, teilweise cystisch degeneriertes Gliom des linken Schläfelappens handelte, von welchem eine so erhebliche Masse entfernt wurde, daß eine enteneigroße Höhle zurückblieb, erfolgte der Exitus letalis nach einem Monat, ebenfalls infolge von Meningitis purulenta. Bei Fall 1 trat zunächst nach teilweiser Auslöffelung der Geschwulst eine wesentliche Besserung der allgemeinen Hirndrucksymptome und auch der sensorisch-aphasischen Störungen ein. Später verschlimmerte sich der Zustand aber wieder, entsprechend der weiteren Größenzunahme der Geschwulst. Der Tod erfolgte ohne weitere Komplikation ein Vierteljahr nach der Operation. Bei dem fünften Fall schließlich stellte sich als Folge der teilweisen Entfernung des Tumors nach der Operation eine linksseitige Hemiparese ein; die Hirndrucksymptome gingen aber so erheblich zurück, daß der Kranke zur Zeit seiner Entlassung, zehn Monate nach der Operation, frei von Allgemeinerscheinungen war.

Was den direkten Einfluß der Hirnpunktion auf das Befinden der Patienten angeht, so war in dem ersten Falle eine vorübergehende Besserung des Befindens im Anschluß an die Punktion, bei welcher mehrere Kubikzentimeter Cystenflüssigkeit entleert waren, zu konstatieren. Irgendwelche nachteiligen Erscheinungen traten bei keinem von diesen Fällen ein. Auch waren bei der nachfolgenden Operation der Fälle, abgesehen von einer geringen bräunlichen Verfärbung in der Umgebung der Punktionsstelle im Falle 3 niemals eine Spur von Blut oder Blutresten und niemals irgendwelche entzündlichen Erscheinungen nachzuweisen. Bei dem 1. Falle war zwar der hintere Ast der Arteria meningea media direkt durchbohrt worden. Dieses Ereignis hatte jedoch nicht den geringsten Bluterguß hervorgerufen, sondern die Gefäßenden hatten sich, wie sich bei der 5 Tage später vorgenommenen Operation zeigte, retrahiert und waren thrombosiert.

\section{Krankengeschichten der Fälle, die nach positivem Resultat der Hirn- punktion zur Sektion kamen, ohne daß eine Operation vorgenommen wurde.}

1. H., Gottlieb, 44jähriger Gastwirt aus Rödchen. Aufnahme: 10. April 1906. Anamnese: Vor 10 Jahren Stoß gegen die Magengegend. Seit einem halben Jahr magenleidend. Seit 4 Wochen Entwicklung einer Geschwulst an der linken Seite des Kopfes. Vor 3 Wochen Anfall von Bewußtlosigkeit mit nachfolgender Lähmung des rechten Armes. Luetische Infektion zugegeben. Schmierkur eingeleitet. 
Status: Auf dem Schädel entsprechend der linken Centro-Parietalregion nahe der Medianlinie eine fast hühnereigroße, flach aus dem Niveau herausragende harte Geschwulst. Beiderseits Stauungspapille. Facialisschwäche rechts. In der Magengrube eine ca. $5 \mathrm{~cm}$ lange vertikal verlaufende Operationsnarbe. Stenose des Oesophagus in der Nähe der Cardia. Hemiparesis dextra spastica. Starke Herabsetzung des Sehvermögens.

Verlauf: Krampfanfälle von Jacksonschem Typus an der rechten Gesichtshälfte beginnend. Schweißausbrüche auf die rechte Seite beschränkt. Verwaschene Sprache mit Andeutung von Silbenstolpern und Paraphasien. Störung der Wortfindung.

Klinische Diagnose: Carcinoma metastaticum oder gummöse Wucherung an der linken Centro-Parietalgegend.

Am 7. Mai Hirnpunktion durch die Geschwulst am Schädel. In $5 \mathrm{~cm}$ Tiefe ein Widerstand. Es wird mißfarbene, blutig-schmierige Flüssigkeit in reichlicher Menge aspiriert, die auch Gewebsteilchen enthält.

Mikroskopisch: Schlauchförmig angeordnete Züge von großen epithelialen Zellen. Diagnose: Carcinom.

Eine vorher eingeleitete $\mathrm{Hg}$-Kur wird daraufhin ausgesetzt.

Exitus am 11. Mai 1906.

Sektionsbef und: In der linken Centro-Parietalgegend wölbt sich eine etwa apfelgroße Geschwulst vor. Dieselbe hat dic Schädelkapsel zum Teil zerstört und erstreckt sich in gleichem Umfange mehrere Zentimeter tief ins Gehirn hinein.

Mikroskopisch: Carcinommetastase eines primären Magencarcinoms.

$$
\text { Epikrise: }
$$

An der Lokaldiagnose der Geschwulst konnte in diesem Falle kein Zweifel herrschen, da dieselbe sich schon äußerlich durch die Vorwölbung an der linken Centro-Parietalgegend dokumentierte. Dagegen war es bezüglich der Art des Tumors zweifelhaft, ob es sich um eine Carcinommetastase oder um eine gummöse Wucherung am Schädeldach handelte. Da die letztere Möglichkeit in Betracht gezogen war, war bei $\mathrm{H}$. eine Schmierkur eingeleitet worden.

Durch die Hirn pu nktion im Bereich der Vorwölbung an der linken CentroParietalgegend wurde mit Sicherheit festgestellt, daß ein metastatisches Carcinom vorlag. Die $\mathbf{H g}$-Kur wurde darauf ausgesetzt. Nachdem 5 Tage später der Exitus letalis eingetreten war, ergab die Sektion, daß die von einem primären Magencarcinom ausgegangene Carcinommetastase die Schädelkapsel zerstört hatte und sich mehrere Zentimeter weit in das Gehirn hineinerstreckte. Eine operative Entfernung der Hirnmetastase erschien nicht indiziert, weil der Kranke sich bereits in sehr desolatem Zustand befand und das primäre Magencarcinom von chirurgischer Seite als inoperabel erklärt war.

2. Pf., Wilhelm, 21 jähriger Heizer. Aufnahme: 28. März 1908.

A nam nese: Beginn der Erkrankung 2 Monate vor der Aufnahme mit starken Kopfschmerzen, Schwindel und Erbrechen. Mitte März rasche Abnahme des Sehvermögens bis zu fast völliger Erblindung.

Status: Gehen und Stehen völlig unmöglich. Vorher bestand schwankender Gang mit Neigung, nach hinten umzufallen. Starke Rumpfataxie, Kopf hängt gewöhnlich nach vorn. Heftige Schmerzen im Nacken und Hinterkopf. Beim Sitzen fällt Patient bald nach rechts, bald nach links um. Starke Druckempfindlichkeit der Occipitalnerven. Die Pupillen reagieren spurweise auf Licht. Der rechte Bulbus ist vorwiegend nach medialwärts, der linke nach unten gerichtet. Völlige Amaurose. Stauungspapille mit weit vorgeschrittener Atrophie der Sehnerven. Rechte Nasolabialfalte vielleicht etwas deutlicher ausgesprochen als linke. 
Im linken Facialisgebiet zuweilen fibrilläres Muskelzucken. Gehör links stark herabgesetzt ohne Ohrspiegelbefund. Kauen stark verlangsamt. Sprache ebenfalls verlangsamt, doch ohne Stolpern. Knie- und Fersenreflexe beiderseits gesteigert. Muskeltonus an allen Extremitäten ziemlich schlaff. Fußklonus beiderseitig. Kein Babinski. Oppenheim beiderseits vorhanden. Patient ist somnolent; läßt Urin unter sich.

Klinische Diagnose: Tumor des linken Kleinhirns bzw. des linken Kleinhirn-Brückenwinkels.

Hirnpunktion am 30. März 1908.

1. Punktion des rechten Seitenventrikels. Der Ventrikel wird vom rechten Ventrikelpunkt aus in $3 \mathrm{~cm}$ Hirntiefe erreicht. Es fließt unter hohem Druck Ventrikelflüssigkeit aus, wovon $30 \mathrm{ccm}$ entleert werden. Zugleich wird ein $1 \mathrm{~cm}$ langer Hirnzylinder aspiriert.

2. Punktion am linken Kleinhirnpunkt. In $11 / 2 \mathrm{~cm}$ Hirntiefe werden durch Aspiration 2-3 ccm einer öligen Flüssigkeit gewonnen, die schon nach 1-2 Minuten zu einer gelatinösen Masse erstarrt. Innerhalb derselben findet sich ein grauroter Gewebsfetzen.

3. Punktion am rechten Kleinhirnpunkt. Einstich der Punktionsnadel bis $2 \mathrm{~cm}$ Hirntiefe und Aspiration reichlicher Partikelchen.

Mikroskopisch: In dem aus dem linken Kleinhirn gewonnenen Gewebe findet sich ein Stückchen, das aus dicht aneinander gelagerten, meist runden, ziemlich großen Zellen besteht, welche ein dunkelbraunes Pigment enthalten.

Diagnose: Melanom der linken Kleinhirnhemisphäre.

Dàs aus der rechten Kleinhirnhemisphäre aspirierte Gewebe zeigt mikroskopisch norinales Aussehen.

Am Tage nach der Punktion Kopfschmerzen viel geringer. Patient verhält sich ruhig und klagt nicht, während er vorher fortwährend vor Schmerzen gestöhnt hat.

Am 1. April 1908 nach der chirurgischen Klinik verlegt.

Die Operation wird dort wegen des schlechten Allgemeinbefindens und der inzwischen wieder stärker gewordenen Benommenheit des Patienten nicht mehr vorgenommen.

Exitus letalis am 4. April 1908.

Sektion am 5. April 1908.

Bohrkanäle am rechten Stirnhirn und beiderseits an der Hinterhauptsschuppe ohne Veränderung der Umgebung. Am hinteren Pol der linken Kleinhirn hemisphäre findet sich ein taubeneigroßer Tumor, blaurot verfärbt, an den sich nach vorn und unten eine ebenso große, mit klarem Serum gefüllte, glattwandige Cyste anschließt. Der Tumor, bzw. die Cyste erstreckt sich nach rechts hin in den Wurm des Kleinhirns und reicht bis nahe an das Dach des vierten Vontrikels. Die Ventrikel sind stark dilatiert; ebenso der Aquaeductus Sylvii. Am vorderen Pol des rechten Seitenventrikels sieht man eine rötlich gefärbte Punktionsöffnung im Ependym.

Diagnose post mortem: Tumor cerebelli (linke Hemisphäre). Hochgradiger Hydrocephalus internus.

Mikroskopischer Befund: Gewebe aus ziemlich großen runden Zellen, die zum Teil alveoläre Anordnung zeigen. Sowohl diese Zellen als auch besonders die spindeligen Zellen des Zwischengewebes enthalten reichlich dunkelbraunes Pigment.

Diagnose: Melanom.

$$
\text { Epikrise: }
$$

Bei dem Kranken traten in relativ kurzer Zeit die Allgemeinsymptome eines Hirntumors auf. Besonders machte sich schon frühzeitige Sehstörung bemerkbar, 
die in rascher Progression zur Erblindung führte. Schon dieser Umstand wies auf eine Lokalisation in der hinteren Schädelgrube hin. Aber auch die sämtlichen Lokalsymptome, wie die Gleichgewichtsstörung, die sich anfangs in taumelndem Gang äußerte und später zur völligen Abasie und Astasie führte, die Rumpfataxie, die abnorme Kopfhaltung, die Schmerzen im Genick und Hinterkopf, sowie die Kombination von Hypotonie und spastischen Symptomen der unteren Extremitäten sprachen für Kleinhirntumor. Bezüglich der Seite des Sitzes der Geschwulst verwies die linksseitige Facialisparese von basalem Charakter kombiniert mit linksseitiger Hörstörung auf die linke Seite. Zweifelhaft konnte es wohl noch sein, ob es sich um einen linksseitigen Kleinhirntumor oder um einen Tumor des linken Kleinhirnbrückenwinkels handelte. Jedoch sprach der rasche Eintritt der Erblindung und das starke Hervortreten der Gleichgewichtsstörungen mehr für eine Lokalisation im Kleinhirn selbst.

Es wurden im ganzen drei Hirnpunktionen vorgenommen, und zwar zunächst eine Ventrikelpunktion zur Druckentlastung. Die Entleerung von $30 \mathrm{ccm}$ klarer Ventrikelflüssigkeit hatte den Erfolg, daß die vorher sehr heftigen Kopfschmerzen am folgenden Tage viel geringer waren. Bei zwei Kleinhirnpunktionen wurden aus der linken Kleinhirnhemisphäre etwa $3 \mathrm{ccm}$ einer öligen Flüssigkeit, sowie ein grauroter Gewebsfetzen aspiriert, der sich mikroskopisch als Melanom erwies, während bei der rechtsseitigen Punktion normales Kleinhirn festgestellt wurde.

Nachdem der Kranke einige Tage nach der Hirnpunktion in die chirurgische Klinik verlegt war, verschlechterte sich sein Allgemeinzustand wieder derartig, daß ein operativer Eingriff nicht mehr vorgenommen wurde. Nach weiteren 3 Tagen erfolgte der Exitus letalis. Bei der Sektion fand sich am hinteren Pol der linken Kleinhirnhemisphäre ein taubeneigroßes Melanom, an welches sich nach vorn hin eine etwa ebenso große Cyste anschloß. Der Tumor wäre, falls die Operation noch gewagt worden wäre, nicht radikal zu entfernen gewesen, da er sich, wie ein Frontalschnitt zeigte, auch nach rechts hin in den Wurm hineinstreckte.

3. K., Friedrich, 68jähriger Ziegelmeister. Aufnahme: 20. Dezember 1909.

Anamnese: Mai 1909 zeitweilig Gefühl von Taubheit im linken Bein. Dazu kamen später Schmerzen im linken Knie und Hüftgelenk. Das linke Bein wurde steifer und schwerfälliger. In den folgenden Wochen Krämpfe im linken Bein; später auch in der linken Rumpf- und Armmuskulatur. Vor Eintritt der Krämpfe meist Gefühl von Kribbeln und Taubsein. Während der Krämpfe Schwindelgefühl im Kopf.

Status: Arteriosklerose. Manchmal Schmerzen im Genick. Augenhintergrund normal. Schwerhörigkeit infolge früher durchgemachten Scharlachs. Parese des linken Beines. Patellarreflex links $>$ rechts. Ausgesprochener Fußklonus links. Babinski links vorhanden. Passive Beweglichkeit der Beingelenke links stark vermindert.

Verlauf: Häufig Krampfanfälle von Jaksonschem Typus. Manchmal nur die linke Rumpf- und Schultermuskulatur betreffend. Händedruck links $<$ rechts. Schwanken beim Greifen nach feinen Gegenständen. Neigung vorwiegend die rechte Hand zu gebrauchen. Tricepsreflex links etwas $>$ rechts. Zunehmende Parese des linken Armes.

Klinische Diagnose: Tumor oder arteriosklerotische Erweichung am oberen Teil der rechten Centro-Parietalgegend.

Hirnpunktionen am 14. Januar 1910.

1. Punktion an der rechten motorischen Region in Höhe des Beinzentrums. 
2. Punktion an der rechten motorischen Region in Höhe des Armzentrums.

Von beiden Stellen aus werden graurötlich aussehende Hirnpartikelchen aspiriert.

Mikroskopisch: Eine Menge homogener, strukturloser Schollen. Mangelhafte Kernfärbung, nur an einer Stelle ein zellreiches Gewebe. Die Zellen haben runde und längliche Kerne mit wenig Protoplasma, das deutliche Ausläufer zeigt.

Diagnose: Gliom mit erweichter Umgebung in der rechten motorischen Region.

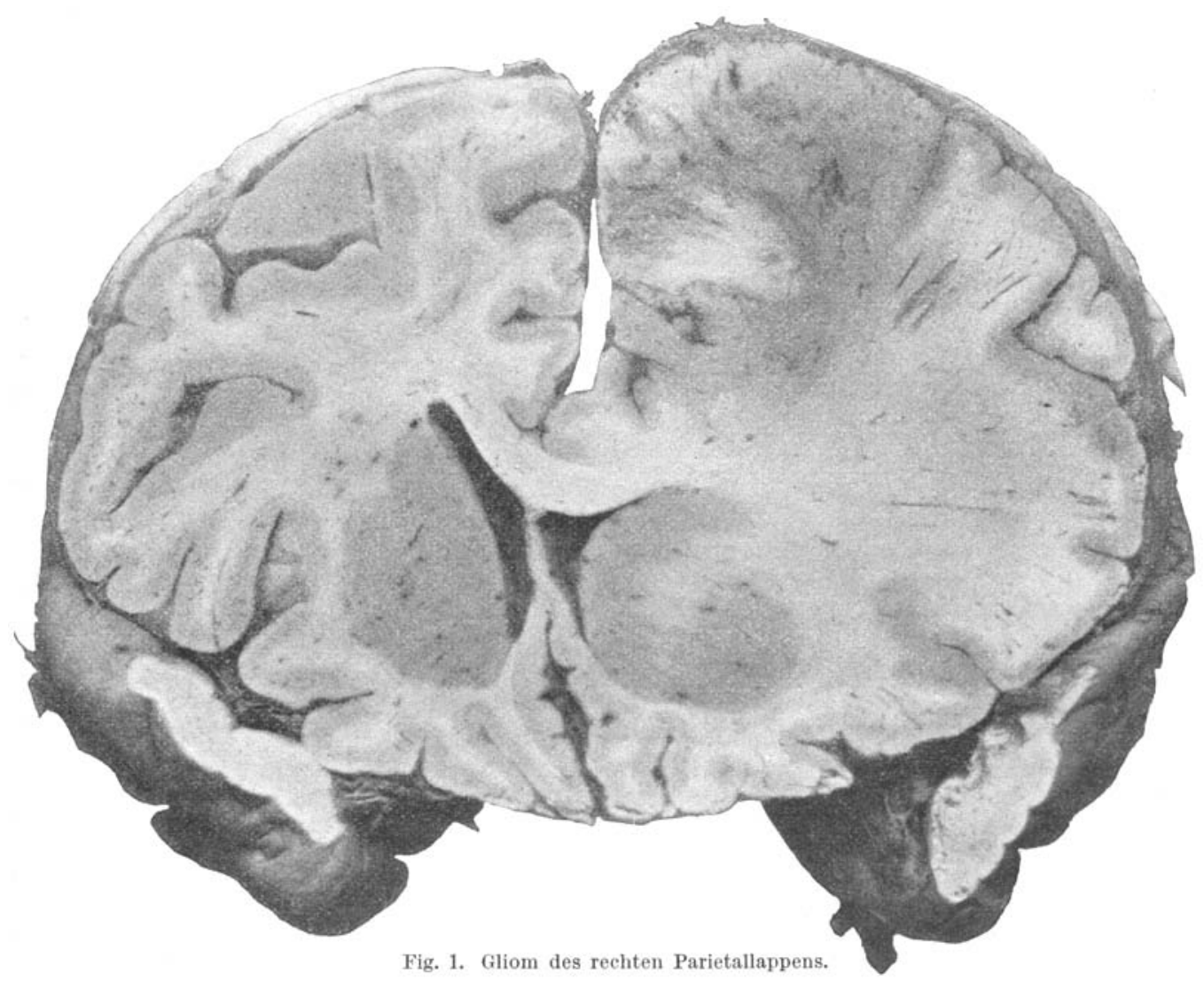

Weiterer Verla uf: Leichte linksseitige Facialisschwäche. Blick vorwiegend nach rechts gerichtet. Beim Linksdrehen des Blicks geht gewöhnlich der Kopf mit. Hemianopsie links. Die Aufmerksamkeit nach links ist schwieriger zu fixieren als nach rechts. Leichte Hypalgesie, Hypästhesie und Lagegefühlsstörung links. Psychisch: Korsakowsche Symptome; nachts häufig delirantes Verhalten.

Exitus letalis am 11. April 1910.

Sektionsbefund: An der linken Hemisphäre Windungen schmal, Furchen tief, an der rechten dagegen Windungen platt, Furchen verstrichen. Die obersten Partien des rechten Zentral- und Parietallappens sind vorgewölbt, graurot, teilweise gelblich verfärbt, derber als die Umgebung: Tu mor im rech te $n$ CentroParietallappen. 
Mikroskopisch: Verschiedengestaltige Zellen mit großen Kernen und zahlreiche Ausläufer zeigendem Protoplasma.

Diagnose: Gliom.

$$
\text { Epikrise: }
$$

Allgemeinsymptome eines Hirntumors waren in diesem Falle nicht sehr deutlich ausgesprochen. Vor allem fehlte die Stauungspapille. Die Schwindelgefühle konnten bei dem alten Mann, der eine ausgesprochene Arteriosklerose der peripheren Arterien aufwies, mit einer Arteriosklerose der Hirnarterien zusammenhängen. Dagegen waren hier sehr charakteristische Lokalsymptome vorhanden. Der Beginn des Leidens mit Parästhesien im linken Bein, woran sich später lokalisierte Krämpfe im Bereich der linken unteren Extremität anschlossen, die im weiteren Verlauf auch auf die linke Rumpfseite und den linken Arm übergingen und die schlicBlich eine linksseitige spastische Parese im Gefolge hatten, sprachen für einen anfänglich ziemlich circumscripten Prozeß im rechten Beinzentrum, zumal im Beginn der Frkrankung die Allgemeinsymptome sehr gering waren. Der progressive Verlauf des Leidens sprach trotz des Fehlens stärkerer Allgemeinerscheinungen, insbesondere der Stauungspaille, dafür, daß es sich um einen Hirntamor handelte. Diese Vermutung fand ihre Bestätigung durch das Resultat zweier Hirnpunktionen, welche an der rechten motorischen Region im Bereich des Bein- und Armzentrums vorgenommen wurden. Auf Grund dieser Hirnpunktionen konnte das Vorliegen eines Glioms mit erweichter U mgebung festgestellt werden. Ein operativer Eingriff zur Entfernung des Tumors war in diesem Falle aus äußeren Gründen nicht zu ermöglichen. Der Kranke starb etwa ein Vierteljahr nach der Punktion. Bei der Autopsie wurde ein Gliom im rechten Centro-Parietallap pen festgestellt.

4. G., Luise, 20jähriges Dienstmädchen, aus Halle. Aufnahme: 18. Januar 1910.

Anamnese: Seit einem Vierteljahr Klopfen im Hinterkopf, besonders des Morgens. Manchmal auch Erbrechen bitterer, wässeriger Massen. In den letzten Tagen 1Doppeltsehen. Kein Anhalt für Lues.

Status: Beiderseits Staungspapille, reehts 4, links 6 Dioptrien. Leichte nystagmusartige Zuckungen des rechten Bulbus beim Blick nach rechts. Facialisschwäche links. Träge Pupillenreaktion auf Licht beiderseits. Puls schwankt zwischen 48 und 96 pro Minute. Keine Sprach-, Schreib- oder Lesestörung, keine Hemianopsie, keine paretischen und ataktischen Erscheinungen.

Starke Kopfschmerzen, gleichnamige Doppelbilder beim Blick nach rechts. Erbrechen und zeitweilige Benommenheit.

Am 28. Januar 1910 Balkenstich in der chirurgischen Klinik. Balken an zwei Stellen perforiert. Liquor entleert sich langsam.

Es wird mit der Sonde in der Tiefe eine elastische Resistenz gefühlt, die als Tumor an der Basis des linken Seitenventrikels gedeutet wird.

16. Februar. Nach Zurückverlegung aus der chirurgischen Klinik weniger Kopfschmerzen. Bisweilen noch Doppeltsehen. Sehen verschlechtert. Stauungspapille links 7, rechts 5 Dioptrien. Homonyme rechtsseitige Hemianopsie. Die rechte Hand zittert beim Vorstrecken etwas. Rechts deutliche Ataxie beim FingerNasen-Versuch. Lagegefühl rechts deutlich gestört, sowohl bei direkter als bei indirekter Prüfung. Grobschlägiges Zittern des rechten Fußes beim Erheben. Kniescheibenreflexe rechts > links. Spontansprache intakt, ebenso Sprachverständnis und Nachsprechen. Dagegen besteht ausgesprochene amnestische Aphasie. Ferner Alexie und Agraphie. Der eigene Name und Zahlen können zwar geschrieben werden. Spontanschreiben ist aber im übrigen fast unmöglich. Diktatschreiben mangelhaft. Lesen sehr schwer gestört. Die Kranke sieht die einzelnen Buchstaben und kann sie auch nachzeichnen. Sie versteht jedoch die Bedeutung der 
Buchstaben nicht, selbst wenn sie sie nachgeschrieben hat. Lesen von Zahlen gelingt besser.

Klinische Diagnose: Tumor des linken Scheitellappens.

Am 29. März 1910 Hirnpunktion.

1. Am linken Gyrus angularis Dura in $2 \mathrm{~cm}$ Tiefe durchstochen. Einstich bis $31 / 2 \mathrm{~cm}$ Hirntiefe. Erst beim Zurückziehen der Punktionsnadel wird in etwa $3 \mathrm{~cm}$ Hirntiefe Liquor cerebrospinalis aspiriert. Außerdem ein $1 \mathrm{~cm}$ langer graurötlicher Gewebszylinder.

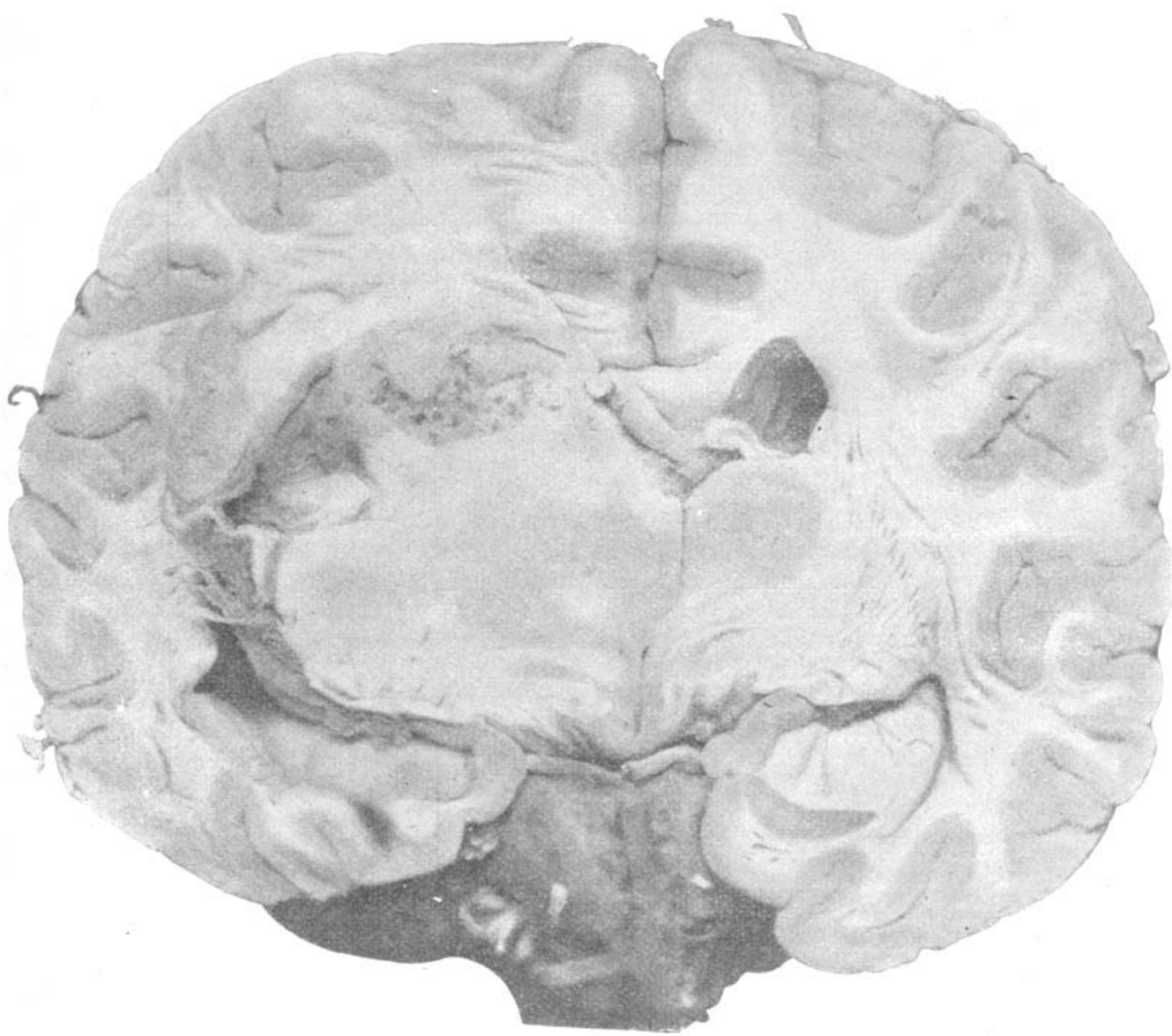

Fig. 2. Endotheliom des linken Hirnstamms, den linken Seitenventrikel ausfüllend, mit Druckwirkung auf den linken Parietallappen.

2. Eine nochmalige Punktion durch das gleiche Bohrloch ergibt genau das gleiche Resultat. Auch hierbei wieder erst beim Zurückziehen der Punktionsnadel in etwa $3 \mathrm{~cm}$ Hirntiefe Ventrikelflüssigkeit.

3. Punktion am linken oberen Scheitelläppchen, $2 \mathrm{~cm}$ oberhalb des ersten Bohrlochs. Einstich bei $3 \mathrm{~cm}$ Hirntiefe und Aspiration. Punktion resultatlos. 
4. Bei nochmaliger Punktion durch das gleiche Bohrloch bis $3 \mathrm{~cm}$ Hirntiefe werden mehrere graurötliche Gewebspartikelchen aspiriert.

Mikroskopisch: Die bei der Punktion gewonnenen Gewebsstücke bestehen aus dicht aneinander gelagerten spindeligen Zellen, mit vereinzelten konzentrischen Schichtungen.

Diagnose: Endothelion des linken Scheitellappens.

Punktion gut vertragen. Der vorher sehr frequente Puls sinkt nach der Punktion auf 64 Schläge in der Minute.

Wegen des sehr schlechten Allgemeinzustandes, insbesondere andauernder Somnolenz wurde ein operativer Eingriff nicht mehr vorgenommen.

Am 5. April 1910 erfolgte der Exitus letalis.

Sektionsbefund: An der rechten Schädelhälfte, $2 \mathrm{~cm}$ von der Sagittalnaht entfernt eine kleine Trepanationsöffnung (Balkenstich). Am linken Schädeldach in der Parieto-Occipitalgegend zwei Bohrlöcher (Hirnpunktion). Im Bereich der Himpunktionskanäle sowie des Balkenstichkanals kein Anzeichen von Blut oder Blutresten. Die linke Gehirnhälfte ist voluminöser als die rechte. Am stärksten vorgewölbt ist die Gegend des Parietalhirns.

In den linken Seitenventrikel und in das Hinterhorn wölbt sich ein vom Hirnsta m ausgehender, etwa a pfelgroßer Tu mor vor, der den hintersten Teil des linken Seitenventrikels völlig verschließt. Derselbe ist teils graurötlich, teils gelb verfärbt und stellenweise kolloid entartet.

Die von dem Tumor gedrückten Partien des Temporal- und Parietallappens sind erweicht.

Mikroskopisch: Endotheliom.

$$
\text { Epikrise: }
$$

Bei dieser Kranken hatten sich im Verlauf von einem Vierteljahr sehr rasch schwere allgemeine Hirndruckssymptome entwickelt, so daß bei ihrer Aufnahme in der Klinik an der Allgemeindiagnose eines Hirntumors kaum zu zweifeln war.

Dagegen waren die Lokalsymptome anfangs nicht leicht zu deuten. Die gleichnamigen Doppelbilder und die nystagmusartigen Zuckungen des rechten Bulbus beim Blick nach rechts entsprachen einer rechtsseitigen Abducensparese, deren Kombination mit einer linksseitigen Facialisparese am ehesten durch einen Tumor des Hirnstammes bzw. der Hirnbasis zu erklären gewesen wäre. Jedoch genügte der klinische Befund keineswegs für eine einigermaßen begründete Lokaldiagnose. Wegen der hochgradigen Stauungspapille von rechts 4, links 6 Dioptrien wurde zunächst zur Druckentlastung der Balkenstich ausgeführt. Dabei wurde mittels der zum Balkenstich benützten Hohlsonde an der Ventrikelbasis in der Mittelhirngegend eine elastische Resistenz gefühlt, eine Beobachtung, die nunmehr einen Sitz der Geschwulst im Hirnstamm wahrscheinlich machte. Naoh dem Balkenstich trat insofern eine Besserung der Allgemeinsymptome ein, als die Kopfschmerzen geringer wurden. Dagegen verschlechterte sich das Sehvermögen mehr und mehr. Außerdem traten nunmehr allmählich auch sehr ausgesprochene Lokalsymptome von seiten des linken Scheitellappens auf in Form von rechtsseitiger homonymer Hemianopsie, rechtsseitiger Ataxie und Lagegefühlsstörung, sowie isolierter Alexie und Agraphie.

Der klinische Befund wies also jetzt ganz entschieden auf eine Lokalisation der Geschwulst im linken Scheitellappen hin.

Es wurden nunmehr vier Hirnpunktionen und zwar jeweils zwei vom gleichen Bohrloch aus am linken Gyrus angularis und $2 \mathrm{~cm}$ oberhalb desselben am linken oberen Scheitelläppchen gemacht. Die von diesen beiden Regionen aspirierten Gewebszylinder erwiesen sich als Endotheliom. Eigen- 
tümlich war die Tatsache, daß bei den beiden Punktionen vom linken Gyrus angularis aus jedesmal beim Einstechen bis $31 / 2 \mathrm{~cm}$ Hirntiefe keine, dagegen beim Zurückziehen der Nadel in $3 \mathrm{~cm}$ Hirntiefe jedesmal etwa $3 \mathrm{ccm}$ Ventrikelflüssigkeit aspiriert wurde.

Auf Grund der Punktionsergebnisse war nunmehr anzunehmen, daß es sich um ein Endotheliom des linken Parietallappens handle. Ein weiterer operativer Eingriff konnte wegen des sehr schlechten Allgemeinbefindens der Kranken nicht mehr vorgenommen werden. Etwa eine Woche nach den Punktionen erfolgte der Exitus letalis.

Die Sektion hatte das überraschende Ergegnis, daß der Tu mor doch nicht im linken Scheitellappen, sondern dicht unter demselben im linke n Hirnsta m m saß. Von hier aus wölbte er sich so weit gegen den Seitenventrikel vor, daß er denselben fast völlig ausfüllte und gegen dessen seitliche parietale Wandung drückte. Die Geschwulst war offenbar beim Balkenstich an richtiger Stelle gefühlt worden. Parietalsymptome traten erst nach dem Balkenstich hervor, weil sich vorher zwischen dem Tumor und dem Scheitellappen, der mit Liquor gefüllte Ventrikel befand. Nach Entleerung der Flüssigkeit infolge des Balkenstichs wurden dann die Lokalsymptome von seiten des linken Scheitellappens infolge der Druckwirkung der Geschwulst auf diesen ihr dicht aufliegenden Hirnteil deutlich. Das weitere Wachstum des Tumors ließ die Parietalsymptome dann noch ausgesprochener hervortreten; zumal im Parietallappen allmählich infolge des fortdauernden Druckes eine Erweichung eintrat. Bei der Hirnpunktion wurde das Parietalhirn durch die eingestochene Kanüle offenbar noch dichter an den Tumor gedrängt, so daß sich die Spitze der Punktionsnadel bei $3^{1 / 2} \mathrm{~cm}$ Hirntiefe bereits innerhalb des Tumors befand, ohne daß beim Durchgehen durch den Ventrikelspalt Liquor aspiriert wurde. Beim Zurückziehen der Nadel dagegen wurde der Scheitellappen etwas vom Tumor abgehoben und der Ventrikelspalt erweitert, so daß nunmehr in $3 \mathrm{~cm}$ Hirntiefe Liquor aspiriert wurde. Mit Hilfe der Punktionsnadel war also der Tumor gefunden und seine histologische Beschaffenheit festgestellt worden; jedoch war der Befund nicht richtig gedeutet worden. Eine richtige Beurteilung der Verhältnisse wäre aber wohl intra vitam nur durch eine größere Zahl von Punktionen zur Bestimmung der Tiefe des Sitzes der Geschwulst möglich gewesen.

\section{Sch., Hugo, 52jähriger Konsul aus Mexiko¹.)}

A na m ne se: Patient hatte früher Lues akquiriert und war seit längeren Jahren schon in ärztlicher Behandlung wegen tabischer Symptome. Seit einem Vierteljahr starke Stirnkopfschmerzen, seit mehreren Monaten zunehmende Benommenheit. Brechneigung, Schwindel und unsicherer Gang. Hierzu kam allmählich eine linksseitige Parese. Wegen der heftigen Stirnkopfschmerzen und zeitweise bestehendem Fieber war eine Stirnhöhlenoperation vorgenommen, die aber keine Besserung brachte.

Status: Kräftig gebauter, gut genährter Mann in schwerbenommenem Zustand. Die Aufmerksamkeit ist nur sehr schwer zu erwecken. Patient ist zeitlich und örtlich desorientiert. Die Merkfähigkeit ist stark herabgesetzt, es bestehen Konfabulationen. Die Lichtreaktion der Pupillen ist träge und wenig ausgiebig.

1) Für die Erlaubnis zur Veröffentlichung dieses von mir auswärts punktierten Falles bin ich Exz. Erb, sowie Herrn Dr. von Wild in Frankfurt a. M. zu Dank verpflichtet. Die Punktionen der sämtlichen übrigen Fälle habe ich in der Nervenklinik in Halle vorgenommen, deren Leiter, Herrn Geheimrat Anton, ich auch an dieser Stelle für die Erlaubnis zur Veröffentlichung derselben bestens danke. 
Am Augenhintergrund sind die Papillen ziemlich blaß mit etwas verwaschenen Grenzen. Es besteht linksseitige Facialisparese und linksseitige Hemiplegie.

Eine mehrere Wochen lang durchgeführte Hg-Injektionskur brachte nur vorübergehende Besserung.

Am 15. April 1910 wurden fünf Hirnpunktionen vorgenommen.

1. Am hinteren Teil der ersten rechten Stirnwindung.

2. Am hinteren Teil der zweiten rechten Stirnwindung.

3. An einer Stelle $\mathrm{zwischen} 1$ und 2.

4. Am rechten Schläfenlappen.

5. Am linken Seitenventrikelpunkt.

Es wurde jedesmal ohne Anästhesierung, da Patient völlig benommen war und keinerlei Schmerzen äußerte, bis zu $3 \mathrm{~cm}$ Hirntiefe eingegangen. Von Punkt 1 wurde nur ein kleines derbes Gewebsstückchen, von Punkt 3-5 jedesmal ein längerer Hirnzylinder aspiriert. Ventrikelflüssigkeit war bei keiner Punktion zu gewinnen.

Mikroskopischer Befund ergab bei Punktion 1 Knochengewebe, bei Punktion 4 und 5 normales Hirn, bei 2 und 3 neben normale $m$ Hirn einige Gewebsstückchen mit pathologischer Anordnung und Vermehrung von Gliafasern, an einer Stelle auch mit Vermehrung von Gliazellen.

Diagnose: Wahrscheinlich reaktive Wucherung faseriger Glia in der Umgebung eines tiefer sitzenden raumbeschränkenden pathologischen Prozesses. Gegen eigentliches Gliom spricht der geringe Zellgehalt.

Eine Veränderung des klinischen Befundes trat nach der Punktion nicht ein. Die Vornahme einer Operation wurde auf Grund des Punktionsergebnisses widerraten.

Der Kranke starb, ohne daß sich im Krankheitsbilde etwas Wesentliches geändert hatte, abgesehen von bronchopneumonischen Erscheinungen am rechten Unterlappen, am 25. April 1910.

Die von Herrn Prosektor Dr. Me yer (Frankfurt a. M.) vorgenommene Sektion ergab: Entsprechend den fünf Punktionsöffnungen im Schädel auf der Dura zum Teil mit Knochenspänen bedeckte Öffnungen. In der Umgebung derselben an der Innenseite der Dura rotbräunliche Beläge. Die weichen Hirnhäute sind an den entsprechenden Stellen in geringem Grade blutig imbibiert. Der linke Seitenventrikel ist etwas, der rechte stark erweitert. Aus dem Kopf des Nucleus caudatus ragt nach dem Ventrikel zu ein etwa bohnengroßes gelbliches Knötchen über die Oberfläche heraus. Dasselbe ist mit der Tela chorioidea und dem Plexus chorioideus verwachsen und legt sich direkt vor das Foramen Monroi. Zwei ähnliche kleine Knoten finden sich noch im Velum medullare anterius und post. des Kleinhirns, zum Teil noch auf den Nucleus dentatus übergreifend.

Mikroskopischer Befund: Die Knoten bestanden aus verkäsendem, nekrotischem Gewebe. Untersuchung auf Tuberkelbazillen und Spirochaeten fiel negatib aus. In der Umgebung des Knotens im Nucleus caudatus fanden sich gewucherte Gliaelemente. Außerdem wurde eine mächtige Gliawucherung im Bereich der rechten Großhirnganglien festgestellt.

Diagnose: Auf Grund der klinischen Untersuchung (W. R. + ) sowie aus dem Fehlen sonstiger Tbc-Veränderungen im Körper bei der Sektion wurde geschlossen, daß die Knötchen wahrscheinlich luetischer Natur seien.

\section{Epikrise:}

Bei diesem Kranken entwickelten sich im Verlauf eines Vierteljahres schwere Allgemeinsymptome eines Hirnleidens, wie Stirnkopfschmerzen, Benommenheit, Erbrechen und Schwindel. Wegen eines vorübergehenden akut fieberhaften $\mathrm{Zu}$ - 
standes war ein Stirnhöhlenempyem angenommen worden. Bei Eröffnung der Stirnhöhlen fand sich zwar eine entzündliche Schwellung der Schleimhaut, jedoch trat im Anschluß an die Operation keine Besserung der Allgemeinerscheinungen ein. $\mathrm{Da}$ der Kranke luetisch infiziert gewesen war und früher schon tabische Symptome gezeigt hatte, wurde nunmehr eine Schmierkur eingeleitet, doch brachte auch diese nur vorübergehende Besserung. Die Erscheinungen des Hirndrucks nahmen jetzt mehr und mehr zu. Der Kranke wurde somnolent und zeigte dabei in psychischer Beziehung Erscheinungen einer Korsakoffschen Psychose. Auch die Begrenzung der Papillen wurde jetzt unscharf. Angesichts dieses progressiven Charakters des Leidens kam nunmehr vor allem ein Hirntumor in Frage. Bezüglich der Lokalisation desselben wies die Kombination von Gleichgewichtsstörungen mit einer allmählich sich entwickelnden linksseitigen Hemiparese auf das rechte Stirnhirn hin. Auch der rechte Schläfenlappen konnte in Frage kommen.

Mitte April 1910 wurden fünf Hirnpunktionen vorgenommen und dabei vom hinteren Teil der ersten und zweiten Stirnwindung in $3 \mathrm{~cm}$ Hirntiefe Gewebe mit pathologischer Anordnung und Vermehrung von Gliafasern aspiriert. Hieraus wurde geschlossen, daß eine reaktive Wucherung faseriger Glia in der Umgebung eines noch tiefer sitzenden raumbeschränkenden pathologischen Prozesses vorliege. Auf Grund dieses Befundes wurde ein vorher geplanter operativer Eingriff am rechten Stirnhirn für aussichtslos erklärt und unterlassen.

Die Sektion ergab einen etwa boh nengroßen, im Bereich des Schwanzkernkopfes lokalisierten Geschwulstknoten, der aus nekrotischem Gewebe bestand und in dessen Umgebung sich gew ucherte Gliaele mente vorfanden. Zwei ähnliche kleine Knoten saßen im Velumen medullare anterius und posterius des Kleinhirns.

Der Sektionsbefund ist meines Erachtens durchaus als eine Bestätigung des Ergebnisses der Punktion anzusehen. Bei den beiden Punktionen am hinteren Teil der ersten und zweiten rechten Stirnwindung mußte die Spitze der Punktionsnadel angesichts der vorhandenen hydrocephalischen Erweiterung des rechten Vorderhorns in $3 \mathrm{~cm}$ Hirntiefe dicht am Ventrikelrand, also auch in nächster Ungebung des Schwanzkernkopfes sein. Aus dem mikroskopischen Befund einer Gliafaserwucherung in den Punktionspräparaten war also der richtige Schluß gezogen worden, daß der eigentliche raumbeschränkende pathologische Prozeß noch tiefer sitze und daher inoperabel sei. Tatsächlich ergaben auch die nach der Sektion vorgenommenen mikroskopischen Untersuchungen gewucherte Gliaelemente in der Umgebung des im Nucleus caudatus lokalisierten Geschwulstknotens.

Die bei dem Kranken festgestellte Gleichgewichtsstörung war übrigens retrospektiv wohl mehr durch die zwei Knötchen im Kleinhirn als durch das im Kopf des Nucleus caudatus sitzende bedingt.

\section{Zusammenfassung.}

Die in dieser Gruppe mitgeteilten fünf Fälle kamen zwar nicht zur Operation, sie bieten aber doch insofern besonderes Interesse, als dabei durch die Hirnpunktion bemerkenswerte diagnostische Erfolge erzielt wurden.

In zweien von diesen Fällen, in welchen die klinische Lokaldiagnose richtig gestellt war, gab die Hirnpunktion näheren Aufschluß über die Art des zugrunde liegenden Leidens. So wurde in dem ersten Fall, in welchem bezüglich der Lokaldiagnose kein Zweifel möglich war, 
da die Geschwulst den Knochen durchwachsen hatte und schon äußerlich erkennbar war, durch die Punktion festgestellt, daß es sich um eine carcinommetastase eines primären Magencarcinoms handelte und infolgedessen eine wegen der Möglichkeit des Vorliegens einer gummösen Wucherung vorher eingeleitete Schmierkur abgesetzt. In dem dritten Falle, in welchem auf Grund der klinischen Diagnose eine organische Affektion der rechten Centro-Parietalgegend angenommen war, bezüglich deren Natur es zweifelhaft erschien, ob es sich um einen Tumor oder um eine arteriosklerotische Erweichung handelte, gelang mittels der Hirnpunktion der Nachweis eines Glioms mit erweichter Umgebung.

In dem zweiten Falle schwankte die klinische Diagnose zwischen einem Tumor der linken Kleinhirnhemisphäre und einem solchen des linken Kleinhirnbrückenwinkels. Mit Hilfe der Hirnpunktion wurde hier festgestellt, daß ein cystisch degeneriertes Melanom der linken Kleinhirnhemisphäre vorlag. Der Nachweis eines Melanoms durch Hirnpunktion ist in diesem Falle zum ersten Male gelungen.

Der vierte Fall erwies sich als diagnostisch ganz besonders schwierig. Der klinische Untersuchungsbefund bot anfangs keinen einigermaßen begründeten Anhalt für eine Lokaldiagnose. Bei Vornahme des Balkenstichs wurde dann mit der Hohlsonde an der Ventrikelbasis in der Gegend der linken Seite des Hirnstamms eine abnorme Resistenz gefühlt. Im Anschluß an den Balkenstich ging ein Teil der allgemeinen Hirndrucksymptome zurück. Dagegen traten dann allmählich derartig ausgesprochene Lokalsymptome vonseiten des linken Scheitellappens in den Vordergrund, daß nunmehr klinisch ein Tumor des linken Scheitellappens angenommen wurde. Die Hirnpunktion, durch welche von der Gegend des Scheitellappens aus ein Endotheliom festgestellt wurde, schien diese Diagnose zu bestätigen. Post mortem zeigte sich aber, daß doch ein Tumor der linken Seite des Hirnstammes vorlag, welcher die Parietalsymptome nur durch Nachbarschaftswirkung, anfänglich wohl nur durch Druck und späterhin durch Erzeugung einer Erweichung, hervorgerufen hatte und aus dem bei der Hirnpunktion nach Durchstechung des Scheitellappens Tumormaterial gewonnen war. Daß der Balkenstich nicht nur therapeutisch, sondern auch diagnostisch von Wert sein kann, indem einerseits durch das Zurücktreten allgemeiner Hirndruckerscheinungen Lokalsymptome deutlicher zum Vorschein kommen, andererseits auch mittels der im Ventrikel befindlichen Sonde Tumoren in unmittelbarer Nachbarschaft des Ventrikels direkt gefühlt werden können, ist schon von Anton ${ }^{1}$ ) hervorgehoben worden. In dem vorliegenden Falle war tatsächlich auch eine direkte Betastung des Tumors mittels der Hohlsonde beim Balkenstich möglich gewesen;

1) Anton, Allgemeiner Bericht über 22 Gehirnoperationen mittels Balken. stiches. Med. Klin. 1909, Nr. 48. 
dagegen waren die nach Entleerung von Ventrikelflüssigkeit und dadurch geschaffener Druckentlastung hervorgetretenen Scheitellappensymptome keine direkten Lokalsymptome, sondern Nachbarschaftssymptome des Tumors, was klinisch nicht richtig gedeutet wurde. Ebenso war auch das Resultat der Himpunktion, welches an und für sich ein positives war, nicht richtig gedeutet worden, da die Tiefe, aus welcher die Tumorteilchen gewonnen waren, nicht näher festgestellt worden war.

Wenn auch im allgemeinen die Forderung ihre Berechtigung hat, daß bei einem Patienten die Zahl der Hirnpunktionen auf das Nötigste beschränkt sein sollte, so zeigt doch dieser Fall wieder, daß es manchmal dringend wünschenswert ist, mehrere Punktionen zur Feststellung der Tiefe des Sitzes eines Tumors zu machen, um zu einer sicheren Lokaldiagnose zu gelangen.

Bei dem fünften Fall schließlich, bei welchem die klinische Lokaldiagnose zwischen einem Tumor des rechten Stirnhirns und einem solchen des rechten Schläfenlappens schwankte, gelang es zwar mittels der Hirnpunktion nicht, den Tumor selbst direkt nachzuweisen. Aus dem von dem hinteren Anteil der ersten und zweiten Stirnwindung aus festgestellten Befund eines Gewebes mit Vermehrung und pathologischer Anordnung von Gliafasern wurde aber geschlossen, daß eine reaktive Wucherung faseriger Glia in der Umgebung eines noch tiefer lokalisierten Tumors vorliege, was sich später bei der Sektion durchaus bestätigte. Es fand sich im Schwanzkernkopfe ein gummöser Geschwulstknoten, dessen Umgebung gewucherte Gliaelemente aufwies.

Auch in den übrigen vier Fällen dieser Gruppe, in welchen es gelungen war, mittels der Hirnpunktion die histologische Beschaffenheit der Geschwulst festzustellen, wobei es sich einmal um eine Carcinommetastase, einmal um ein Melanom, einmal um ein Gliom und einmal um ein Endotheliom handelte, wurde die Diagnose jedesmal durch die Sektion bestätigt.

Trotz der durch die Hirnpunktion ermöglichten genauen Diagnosestellung ist keiner von diesen fünf Fällen zur operativen Behandlung gekommen.

Bei dem zweiten und vierten Fall wurde ein operativer Eingriff nach Feststellung der Diagnose wegen des schlechten Allgemeinzustandes nicht mehr gewagt. Eine Operation wäre bei diesen beiden Fällen auch erfolglos gewesen, weil die Tumoren, wie sich bei der Sektion zeigte, inoperabel waren, indem der eine im Hirnstamm saß, der andere sich von der linken Kleinhirnhemisphäre aus in den Wurm hinein erstreckte.

Bei Fall 1 war eine operative Entfernung der Carcinommetastase nicht indiziert, weil der Kranke infolge seines primären Magencarcinoms, das von chirurgischer Seite als inoperabel erklärt war, sich bereits in einem sehr schlechten Kräftezustand befand. 
Bei dem fünften Fall schließlich war auf Grund des Punktionsbefundes welcher auf einen sehr tief sitzenden, inoperabelen Tumor hinwies, von der Vornahme eines operativen Eingriffes abgeraten worden, was sich, wie die Autopsie zeigte als durchaus gerechtfertigt erwies.

Von direkten therapeutischen Folgeerscheinungen der Hirnpunktion wurde unter diesen Fällen zunächst wieder ein vorïbergehendes Nachlassen der Hirndrucksymptome, insbesondere der Kopfschmerzen, bei dem zweiten Falle, im Anschluß an eine Ventrikelpunktion, wobei $30 \mathrm{ccm}$ Ventrikelflüssigkeit entleert wurden, beobachtet. Bei dem vierten Fall hatte die Entleerung der Ventrikelflüssigkeit vorübergehend einen günstigen Einfluß auf den vorher sehr frequenten Puls zur Folge.

Eine durch die Hirnpunktion bedingte Blutung konnte bei den Sektionen in keinem von diesen Fällen konstatiert werden. Nur fanden sich bei dem 5. Falle in der Umgebung der Punktionsstiche an der Innenseite der Dura rotbräunliche Beläge und die weichen Hirnhäute waren an den entsprechenden Stellen in geringem Grade blutig imbibiert.

\section{Nach negativem Resultat der Hirnpunktion zur Sektion gekommene Fälle.}

1. K., Paula, Oberleutnantsgattin aus Prag. Aufnahme: 7. Mai 1906.

A nam nese: Herbst 1904 Kopfschmerzen an Stirn und Nacken. Schwindelgefühl beim Aufrichten und Aufstehen, weniger beim Hinlcgen. Auf Jod-Quecksilberkur geringe Besserung. Sommer 1905 wieder Verschlimmerung, Kopfschmerzen, Sehstörungen, unsicherer Gang, manchmal Erbrechen. Später auch Ohrensausen und Verschlechterung des Gehörs. Anfälle von Umsinken mit Steifwerden des ganzen Körpers und ruckartigen Bewegungen der Arme.

Status: Nystagmus beim Blick nach rechts. Beiderseits Stauungspapille. Linke Pupille reagiert schlechter auf Licht als die rechte. Occipitalpunkte schmerzhaft. Die vorgestreekten Hände zittern grobschlägig rechts > links. Beim Ergreifen feiner Gegenstände Zunahme des Tremors, besonders links. Isolierte Bewegungen der Finger mangelhaft, besonders links. Dabei Mitbewegungen in der anderen Hand. Muskeltonus an beiden Beinen schlaff, besonders rechts. Emporheben der Füßc unter sehr lebhaftem Tremor. Patellarreflexe beiderseits lebhaft. Babinski rechts > links. Fußklonus rechts zeitweise vorhanden, links fehlend. Gang sehr unsicher, Schwanken nach hinten und rechts.

Verla uf: Öfter Schwindelanwandlungen, Zusammensinken, Erbrechen. Sehr rasche Ermüdbarkeit des Gehörs.

Klinische Diagnose: Tu mor cerebelli. (Wahrscheinlich im Bereich des vierten Ventrikels.)

Am 15. Mai 1906 Hirnpunktionen etwas unterhalb des rechten und linken Kleinhirnpunktes. Beiderseits Aspiration von reichlichem grauröt. lichem Gewebe.

Mikroskopisch: Normales Kleinhirn.

Eine Stunde nach der Punktion eigenartiger Krampfzustand. Pat. wälzt sich in drehenden und windenden Rumpfbewegungen im Bett; die Extremitäten sind gebeugt, angezogen; schmerzlich verzerrter Gesichtsausdruck; dabei aber keine Klagen über Schmerzen. Dauer ca. 1/2 Stunde.

16. Mai 1906 Entlassung nach Haus.

17. Juli Exitus. (Sektionsprotokoll von Dr. Verocay aus Prag zugeschickt.) 
Im hinteren Teil des Daches desstark dilatierten vierten Ventrikels findet $\operatorname{sich}$ ein $\mathbf{2 , 5} \mathrm{cm}$ im sagittalen Durchmesser haltender, bis $1,5 \mathrm{~cm}$ hoher, ziemlich weicher Geschwulstknoten, wodurch das Kleinhirn nach oben verdrängt und der Unterwurm abgeplattet wird. Auf dem Durchschnitt zeigt der Tumor opake, graugelbe Farbe. Der Geschwulstknoten ist an der hinteren Hälfte der Rautengrube durch das lamellenartig verdickte Ependym fixiert.

Mikroskopisch: Gliom.

$$
\text { Epikrise: }
$$

An der Allgemeindiagnose eines Hirntumors war bei dieser Kranken nicht zu zweifeln und auch die Lokalsymptome waren durchaus eindeutig. Sie sprachen sämtlich für eine Lokalisation des Tumors in der hinteren Schädelgrube, so namentlich der unsichere taumelnde Gang, die Adiadokokinese, der Nystagmus und Intentionstremor, die mit spastischen Symptomen kombinierte Hypotonie der Beine, die Nackenschmerzen und die Empfindlichkeit der Occipitalpunkte. Das als Brunssches Symptom bekannte plötzliche Zusammenstürzen erlaubte noch eine speziellere Diagnose innerhalb der hinteren Schädelgrube und wies auf einen Sitz des Prozesses in der Umgebung des vierten Ventrikels hin. Obwohl so schon auf Grund der klinischen Diagnose die Aussicht auf einen operativen Erfolg sehr gering erschien, wurden dennoch, da eine Lokalisation der Geschwulst an operabler Stelle immerhin nicht völlig ausgeschlossen war, zwei Hirnpunktionen an den Kleinhirnhemisphären vorgenommen, zumal die Kranke speziell zu diesem Zweck von weither in unsere Klinik gekommen war.

Das Punktat erwies sich beiderseits als normales Kleinhirn und die Lokalisation der Geschwulst im Wurm, bzw. im Bereich des vierten Ventrikels konnte nunmehr als sicher angesehen werden.

Zwei Monate nach der Hirnpunktion starb die inzwischen nach Hause entlassene Kranke. Laut Sektionsprotokoll (Dr. Verocay, Prag) fand sich im hinteren Teil des Daches des stark dilatierten vierten Ventrikels ein überhaselnußgroßes Gliom.

2. W., Friedrich, 25jähriger Hilfsweichensteller aus Benstedt. Aufnahme: 11. Mai 1908.

Anam nese: Januar 1908 angeblich Erkältung. Seitdem ständig starke Kopfschmerzen, Schwindelanfälle, zeitweise Erbrechen, Sehschwäche links.

Status: Schädel leicht klopfempfindlich, besonders in der Nähe der rechten Schläfengegend, etwa in der Mitte zwischen Stirn- und Scheitelhöcker. Schall erscheint daselbst etwas dumpfer. Rechtes Augenlid ein wenig tiefer als linkes. Beiderseits Hyperämie und Schwellung der Opticus-Papille. Umgebung derselben verwaschen; Gesichtsfeld beiderseits frei. Sehvermögen besonders links herabgesetzt. Rechts Trochlearislähmung, die im Rückgange begriffen zu sein scheint. Linke Pupille etwas enger als rechte. Lichtreaktion gut, ebenso Konvergenz. Nystagmoide Zuckungen beim Blick nach rechts. Außerdem besteht beträchtliche Parese des rechten Abducens und ganz leichte Parese des Rectus superior. Supra- und Infraorbitalpunkte und Occipitalpunkte beiderseits gleich druckempfindlich. Rechtes Gaumensegel in der Ruhe etwas tieferstehend, wird auch beim Intonieren nicht so gut gehoben wie das linke. Masseterinnervation anscheinend links < rechts. Tonus der Muskulatur an oberen und unteren Extremitäten herabgesetzt, besonders an den letzteren. Oppenheim beiderseits vorhanden. Nervenstämme sämtlich sehr stark druckempfindlich. Beim Stehen mit gespreizten Beinen deutliches Schwanken, welches bei Fußschluß sehr lebhaft wird und noch ausgeprägter bei Augenschluß. Dabei Neigung zum Fallen nach links und hinten. 
Stehen auf einem Bein schwer möglich, links in verstärktem Maße. Stark taumelnder Gang. Sensibilität aller Qualitäten ungestört.

Klinische Diagnose: Tumor der hinteren Schädelgrube.

11. Mai 1908 zwei Ventrikelpunktionen an den vorderen Stirnpunkten. Rechts bei $5^{1 / 2} \mathrm{~cm}$ Gesamttiefe keine Flüssigkeitsentleerung. Links bei $5 \mathrm{~cm}$ Gesamttiefe unter mäßigem Druck hervorquellende klare Flüssigkeit. Aspiration von ca. $20 \mathrm{ccm}$. Keine Gehirnpartikel.

12. Mai 1908. Erheblich besseres Befinden.

Verlauf: Unter Zunahme der früheren Krankheitssymptome plötzlich am 14. Mai 1908 starkes Erbrechen. Darauf Exitus letalis, bevor die geplante Kleinhirnpunktion stattfinden konnte.

Sektionsbefund: In der hinteren Schädelgrube beiderseits mehrere erbsen- bis hühnereigroße derbe von der Dura ausgegangene Geschwülste. Die Kleinhirnhemisphären sind da, wo sie den Geschwülsten aufgelagert sind, erweicht. Kein Blut im Bereich der Hirnpunktionsstiche und deren Umgebung.

Mikroskopisch: Multiple Durasarkome.

$$
\text { Epikrise: }
$$

Bei dem Kranken hatten sich im Verlauf von wenigen Monaten sämtliche allgemeinen Hirndrucksymptome in ausgesprochenster Weise entwickelt. Auch die Druckempfindlichkeit der Austrittsstellen aller sensiblen Nerven am Kopfe, sowie aller großen Nervenstämme am Körper konnte als allgemeines Hirndrucksymptom bzw. als Folge erhöhten Druckes der Spinalflüssigkeit aufgefaßt werden. Die Lokalsymptome wiesen durchaus auf die hintere Schädelgrube hin, so namentlich das Schwanken beim Stehen, schon ohne Augenschluß, der taumelnde Gang mit Neigung nach links und hinten zu fallen, die Hypotonie der Beine mit beiderseitigem positivem Oppenheimschem Phänomen, die Gaumensegelparese, sowie die Abducens- und Trigeminusschwäche. Das leichte Mitbetroffensein des Oculomotorius und Trochlearis war sehr wohl durch Nachbarschaftswirkung auf das Mittelhirn erklärbar.

Da die Allgemeinerscheinungen sehr erheblich waren und da namentlich der Eintritt baldiger Erblindung zu befürchten war, wurde sofort am Tage der Aufnahme eine Ventrikelpunktion zum Zwecke der Druckentlastung vorgenommen. Da vom rechten vorderen Stirnhirnpunkt in $5 \mathrm{~cm}$ Hirntiefe keine Ventrikelflüssigkeit zu gewinnen war, wurde links an symmetrischer Stelle eingegangen und hier $20 \mathrm{com}$ klaren Liquors entleert. Am Tage nach der Ventrikelpunktion war das subjektive Befinden erheblich besser als vorher.

Nach zwei weiteren Tagen trat wieder plötzlich Verschlimmerung ein, die zum Exitus letalis führte, bevor die geplante Hirnpunktion am Kleinhirn ausgeführt werden konnte.

Die Sektion ergab: Multiple Durasarkome in der hinteren Schädelgrube.

3. D., Luise, 11 jähriges Mädchen aus Gölzau. Aufnahme: 17. September 1907.

Anamnese: Seit einem halben Jahr Kopfschmerzen und Erbrechen; besonders Schmerzen im Hinterkopf. Seit einem Vierteljahr unsicherer schwankender Gang, Nachlassen des Sehvermögens; infolge davon leichtes Ermüden beim Lesen; Erschwerung des Schreibens wegen Zitterns der rechten Hand. Später auch Schwindel und große Mattigkeit.

Status: Beiderseits leichte Ptosis und Schwäche beider N. abducentes links $>$ rechts. Beiderseits hochgradige Stauungspapille mit bereits beginnender Atrophie. Beträchtliche Infiltration. Vortreibung 3-4 Dioptrien. Conjunctivalund Cornealreflex rechts < links. Nystagmus beiderseits. Beklopfen des Schädels 
empfindlich, hauptsächlich links hinten. Occipitalpunkte beiderseits schmerzhaft rechts $>$ links, auch erster und zweiter Trigeminusast links etwas empfindlich. Gesicht auffallend bewegungsarm. Antworten erfolgen langsam. An den Armen zuweilen unwillkürliche Zuckungen, ebenso im Kopf und Rumpfbereich. Grobes Intentionswackeln, ataxieähnlich rechts $>$ links. Knöpfen rechts schlechter als links ausgeführt. Auch am rechten Bein das gleiche Intentionswackeln. Aufrichten aus Rückenlage sehr schwach. Cerebellarer Gang.

Verlauf: Bei späteren Untersuchungen Ohr- und Nasenkitzelreflex rechts herabgesetzt. Leichte Parese des rechten Facialis. Hypotonie der Muskulatur. Rumpfmuskelschwäche. Neigung nach hinten zu stürzen.

Klinische Diagnose: Tumor der hinteren Schädelgrube.

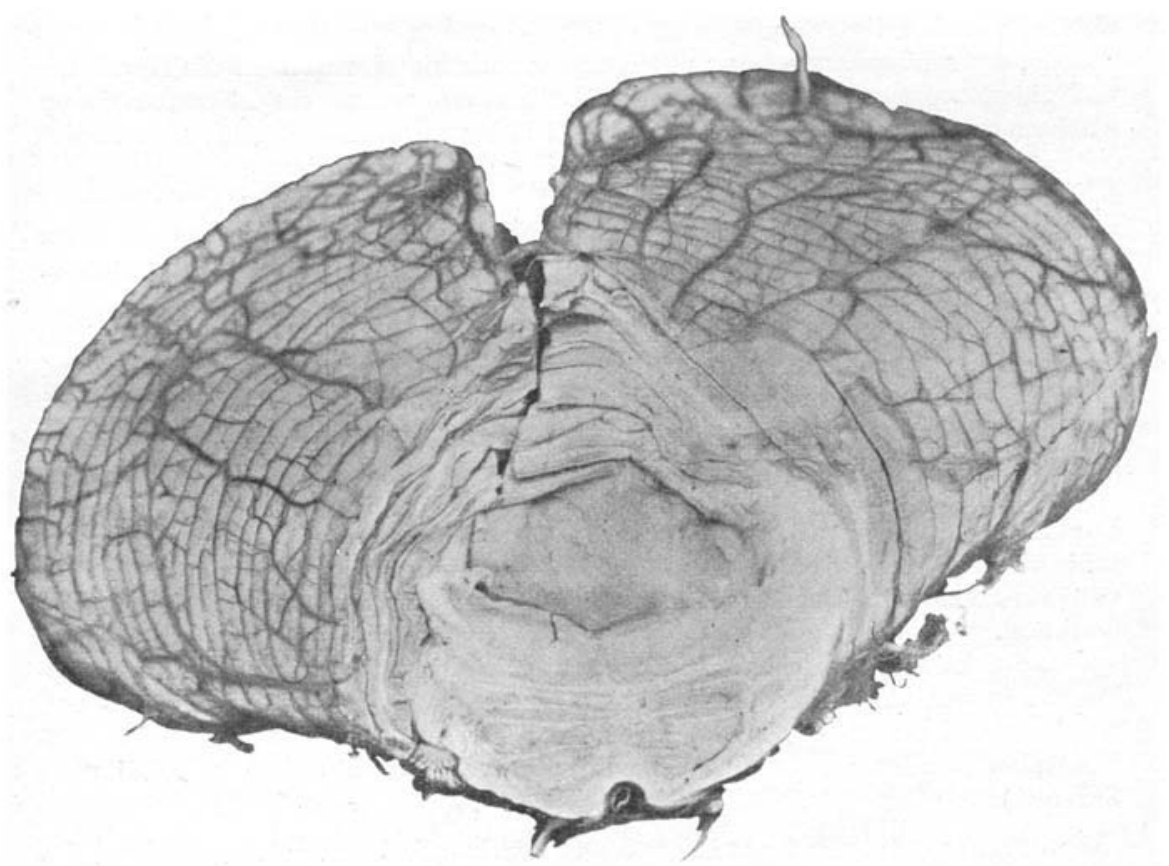

Fig. 3. Tumor des Mittelhirns.

Am 21. Oktober 1907 Hirnpunktionen. Es wird etwas unterhalb der beiden Kleinhirnpunkte punktiert. Die Aspiration ergibt beim Eingehen bis $3 \mathrm{~cm}$ Kleinhirntiefe an beiden Seiten reichlich Hirnmasse.

Punktion gut vertragen.

Mikroskopisch: Normales Kleinhirn.

Weiterer Verla uf: Ausgesprochene Hypotonie der Extremitäten rechts > links. Beiderseits deutliche Ataxie und Adiodokokinesis. Verlangsamung der Aktion der Hauptagonisten bei gleichzeitiger Schwäche derselben. Sprache absolut monoton und leise. Sitzen unmöglich; dabei sofortiges Umsinken nach hinten und rechts. Kopf in leicht epistotonischer Streckstellung. Häufiges Erbrechen. Kopfschmerzen, besonders an der linken Stirnseite. Zunehmende Benommenheit und Schläfrigkeit. Allmählich tritt vollkommene Erblindung ein.

Am 6. November 1907 Exitus letalis. 
Sektions bef und: Hirnwindungen verbreitert. Furchen verstrichen. Zwischen Kleinhirn und Medulla obl. in der Gegend des Foramen Magendie eine längliche zum Teil cystisch entartete Geschwulst, welche sich weiter nach vorn ins Mittelhirn hineinerstreckte und auch die medialsten, direkt dem Wurm anliegenden Teile des Kleinhirns ergriffen hatte. Die Punktionskanäle und deren Umgebung lassen keine Anzeichen einer Blutung erkennen.

$$
\text { Epikrise: }
$$

Die relativ rasche Entwickelung allgemeiner Hirndrucksymptome und namentlich der baldige Eintritt einer Opticusatrophie nach Stauungspapille sprachen schon mit einer gewissen Wahrscheinlichkeit für einen Tumor der hinteren Schädelgrube. Eine Reihe von Lokalsymptomen ließ sich ebenfalls in diesem Sinne verwerten, wie die Hinterkopfschmerzen, die Schmerzempfindlichkeit der Occipitalpunkte, der schwankende Gang mit Neigung nach hinten zu fallen, die Hypotonie und die Rumpfmuskelschwäche. Auch der Nystagmus und das Intentionszittern machten es wahrscheinlich, daß das Kleinhirn, bzw. dessen Verbindungen mit dem Mittelhirn betroffen seien. Die beiderseitige Ptosis, die beiderseitige Abducens. schwäche und die rechtsseitige Facialisschwäche, sowie die Schädigung des rechten sensiblen Trigeminusanteils konnte durch Nachbarschaftswirkung auf die Pons und Vierhügelgegend, bzw, durch direktes Ergriffensein dieser Regionen durch den Tumor bedingt sein.

Zwei Hirnpunktionen am Kleinhirn ergaben, daß die Kleinhirnhemisphären normalen Befund zeigten. Hieraus war zu schließen, daß es sich um einen an den medialen Kleinhirnpartien, also im Wurm lokalisierten und oralwärts gegen die Pons und die Vierhügelgegend drückenden oder dahin gewucherten Tumor handeln mußte, der somit als inoperabel zu betrachten war.

Hierfür sprachen auch die im weiteren Verlauf der Erkrankung nach der Punktion beobachteten Symptome, wie Ataxie und Adiadokokinese, die Monotonie der Sprache, die opistotonische Kopfhaltung, sowie die bald eintretende völlige Erblindung. Der Exitus letalis erfolgte etwa zwei Monate nach der Hirnpunktion.

Die Sektion ergab einen zwischen den Kleinhirnwurm und der Medulla oblongata in den vierten Ventrikel hineinragenden Tumor, der sich nach oral- und basalwärts, also nach der Mittelhirngegend weiter ausbreitete und die Kleinhirnhemisphären selbst nur an ihrem medialsten vordersten Anteil betraf. (Mikrosk. Sarkom.)

4. T., Fritz, 6 jähriger Knabe aus Teutschenthal. Aufnahme: 1. September 1910.

Anamnese: Großvater mütterlicherseits an Tuberkulose gestorben. Seit Mai 1910 viel Kopfschmerzen, öfters auch Erbrechen und zeitweise Schwindel. In letzter Zeit fiel auch unsicherer Gang auf. Mehrfach soll er doppelt gesehen haben.

Status: Kopfumfang $55 \mathrm{~cm}$, Längsbogen $35 \mathrm{~cm}$. Beiderseits ausgesprochene Stauungspapille ohne Anzeichen von Atrophie. Papille beiderseits prominent um etwa 3,5 Dioptrien. Pupillenreaktion beiderseits prompt. Lymphdrüsen am Halse geschwollen. Beim Gehen weicht er von der geraden Richtung bald nach rechts, bald nach links etwas ab; deutliches Schwanken beim Stehen mit geschlossenen Augen und Kehrtwendungen.

Sehnenreflexe an Armen und Beinen lebhaft, ohne sonstige Erscheinungen eines spastischen Zustandes. Ataxie mäßigen Grades an den Beinen, an den Armen dagegen nicht deutlich.

Verlauf: Am Tage nach der Aufnahme vorübergehend Kopfschmerzen, und einmaliges Erbrechen. Vier Tage später anfallsweise mehrere Stunden lang 
starke Kopfschmerzen, mehrmaliges Erbrechen, Puls- und Atemverlangsamung, sehr blasses Aussehen. Eine Woche nach Aufnahme läßt er während der Nacht unter sich; am anderen Morgen leicht benommen, sehr blaß, starker Romberg, erhebliche Pulsverlangsamung (46-54 pro Minute).

Klinische Diagnose: Tumor cerebelli.

Am 8. September $1910\left(10 \frac{1}{2}\right.$ Uhr vorm.) zwei Hirnpunktionen etwas unterhalb der typischen Kleinhirnpunkte. Dabei rechts nach Durchbohrung des Schädels zunächst venöse Blutung, die aber nach einigen Minuten steht. Von beiden Stellen wird bei ler Punktion reichlich Kleinhirngewebe ohne Blut aspiriert.

Mikroskopisch: Normales Kleinhirn.

Weiterer Verlauf: Zwei Stunden nach Punktion vorübergehend verlangsamtes Atmen, starke Pulsverlangsamung, sehr blasses Aussehen und leichte Benommenheit. Später ist er wieder ganz attent und munter, lacht, nimmt Nahrung

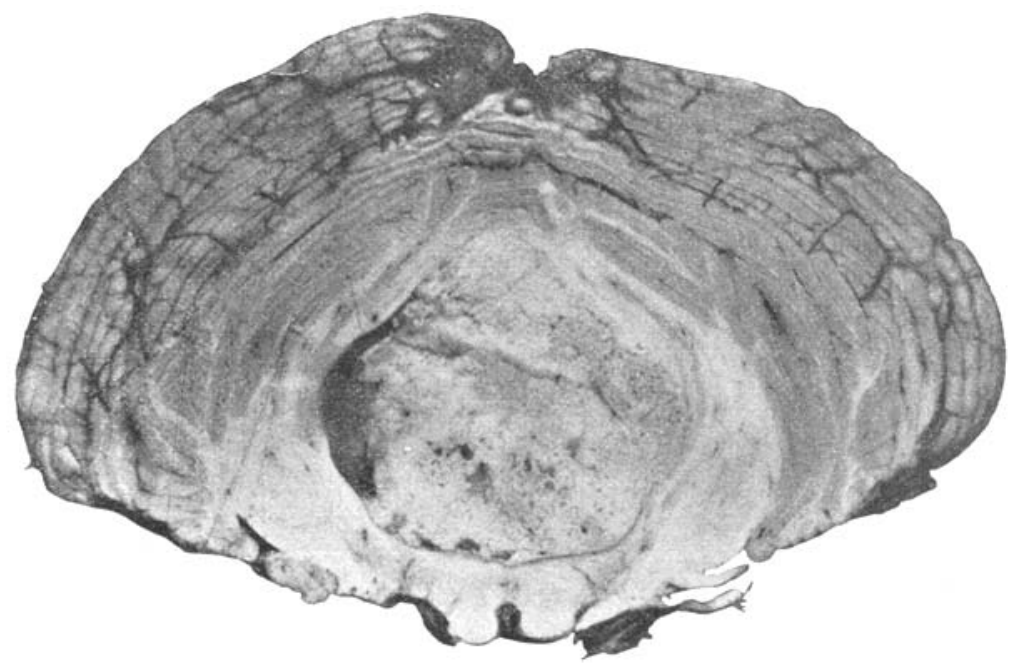

Fig. 4. Spindelzellensarkom, vom Vermis cerebelli ausgehend und den vierten Ventrikel ausfiillend.

zu sich; Puls rascher und kräftiger. Abend 7 Uhr plötzlich starke Pulsfrequenz und Unregelmäßigkeit des Pulses, Cheyne-Stokessches Atmen, Exitus letalis.

Sektionsbefund: WalnuBgroßer, von einer dünnen, mit klarer Flüssigkeit gefüllten Haut (Velum medullare posterius) umgebener, grauweißer Tumor, deraus dem Unterwurm hervorragt und direkt auf dem vierten Ventrikel aufliegt (Spindelzellensarkom). Starker Hydrocephalus internus, Abplattung der Hirnwindungen. In der rechten hinteren Schädelgrube findet sich auf der Innenfläche der Dura eine kaum $1 \mathrm{~mm}$ dicke Schicht von geronnenem Blut. Das Kleinhirn ist an entsprechender Stelle an der Oberfläche etwas blutig imbibiert. Der Punktionsstich geht durch eine oberflächliche Kleinhirnvene. Die Bohrkanäle sind beiderseits $1 / 2 \mathrm{~cm}$ unterhalb der Sinus. Die Medulla oblongata und der Pons sind durch den Tumor stark plattgedrückt. Der Tumor reicht nach vorn bis in den Pons hinein.

\section{Epikrise:}

Bei dem Jungen kamen außer den sonstigen ausgesprochenen Allgemeinsymptomen eines Hirntumors mehrfach sehr bedrohliche Anfälle von Puls- und 
Atemverlangsamung, Blässe und Benommenheit zur Beobachtung, die für einen Sitz der Geschwulst in der hinteren Schädelgrube und zwar in der Nähe der Medulla oblongata sprachen. Auch die allerdings nicht sehr zahlreichen Lokalsymptome in Form von Schwanken beim Stehen und Gehen, Doppeltsehen, Ataxie der Beine bei lebhaften Sehnenreflexen ließen sich sehr wohl auf einen Tumor der hinteren Schädelgrube zurückführen.

Zwei Kleinhirnpunktionen ergaben normalen Befund an den Kleinhirnhemisphären. Dabei floß nach Durchbohrung des Schädels rechts aus der Bohröffnung einige Minuten lang dunkelrotes Blut. Nach dem negativen Resultat der Punktion mußte ein im Wurm sitzender und daher inoperabler Kleinhirntumor angenommen werden.

Zwei Stunden nach der Punktion trat bei dem Kranken wieder einer der oben beschriebenen Anfälle von Puls- und Atemverlangsamung, Blässe und Benommenheit auf. Nachdem der Junge darauf den ganzen Nachmittag sehr munter und mit kräftigem Puls zugebracht hatte, trat abends noch ein zweiter derartiger Anfall ein, welcher den Exitus letalis im Gefolge hatte.

Der Tod war hier zweifellos durch den, wie die Sektion ergab, an besonders lebensgefährlicher Stelle im Bereich des vierten Ventrikels lokalisierten Tumor, der schon mehrfach vor der Punktion ähnliche recht bedrohliche Anfälle hervorgerufen hatte, bedingt. Das minimale subdurale Blutextravasat in der rechten hinteren Schädelgrube dürfte kaum irgendeinen Einfluß auf den ungünstigen Ausgang gehabt haben, zumal der Junge sich den ganzen Nachmittag in der Zeit zwischen dem ersten und zweiten Anfall in recht gutem Zustand befand.

5. Sch., Paul, 12 jähriger Bergmannssohn aus Goddula. Aufnahme: 22. November 1910.

Anamnese: Seit Anfang Oktober täglich morgens Erbrechen. Schwarzwerden vor den Augen. Einmal plötzliches Zusammenstürzen. Vorübergehend 5 Tage lang beschwerdefrei. Dann Rückfall. Seit 8 Tagen Doppeltsehen.

Aus der Augenklinik wegen Stauungspapille hierher geschickt.

Status: Kopf wird nach rechts geneigt gehalten. Kopfumfang $55 \mathrm{~cm}$. Längs- und Querbogen je $35 \mathrm{~cm}$. Beiderseits deutliche Staungspapille, links 4, rechts 3 Dioptrien. Rechtsseitige Abducens- und Trochlearisparese. Doppelbilder beim Blick nach rechts mit Höhendifferenz. Lichtreaktion der Pupillen etwas träge. Zäpfchen weicht etwas nach links ab. Taumelnder Gang, besonders bei Augenschluß und bei Kehrtwendungen.

Sehnenreflexe an den Beinen kaum auszulösen. Deutlich nur der rechte Patellarreflex. Leichte Hypotonie der Beine, links mehr als rechts. Grobe Kraft im linken Arm und Bein schwächer als rechts. Drüsenschwellungen am Halse. Puls verlangsamt (60 p. Min.) und unregelmäßig. Die Wassermannsche Reaktion des Blutes war bei wiederholten Untersuchungen mehrmals negativ, einmal schwach positiv.

Klinische Diagnose: Tumor der hinteren Schädelgrube.

Am 25. November 1910 Ventrikelpunktion am rechten Ventrikelpunkt.

In $3 \mathrm{~cm}$ Hirntiefe fließen $30 \mathrm{~cm}$ Ventrikelflüssigkeit von wasserklarem Aussehen unter starkem Druck ab.

Globulinreaktion und Wassermann negativ. Keine Lymphocytose. Punktion gut vertragen. Subjektives Befinden besser. Die Stauungspapille hat 2 Tage nach der Ventrikelpunktion deutlich abgenommen, rechts 1,5, links 3-4 Dioptrien. Doppelbilder verschwunden. Keine Augenmuskellähmungen mehr nachweisbar.

Am 28. November 1910 Punktionen in der rechten und linken Kleinhirngegend etwa $1 / 2 \mathrm{~cm}$ unterhalb der Mitte der Verbindungslinien 
zwischen Protuberantia occip. externa und Spitze der Proc. mastoideus. (Vorm. 11 Uhr.)

1. Links bis $2 \mathrm{~cm}$ Hirntiefe eingegangen. Die Dura schien bei der Durchstechung sehr derb. Reichliche Gewebspartikelchen aspiriert, die sich bei mikroskopischer Untersuchung als normales Kleinhirn erwiesen.

2. Rechts wird sofort nach Einstich durch die Dura mater in ca. $1 / 4$ bis $1 / 2 \mathrm{~cm}$ Hirntiefe $2-3 \mathrm{ccm}$ dunkelrotes Blut aspiriert. Dasselbe steht unter ziemlich starkem Druck. Punktionsspritze wird sofort herausgezogen.

Zunächst keine Änderung des Befindens. Nach dem Essen Erbrechen. Nachmittags keine Beschwerden. Abends Schmerzen an der linken Stirnseite. Nach dem Abendessen wieder Erbrechen. Nachts Klagen über Kopfschmerzen.

Am nächsten Morgen 7 Uhr Exitus letalis.

Sektionsbefund: Die hintere Schädelgrube ist mit einer zum Teil flüssigen, zum Teil geronnenen Blutschicht bedeckt. Eine ziemliche Menge flüssigen Blutes entleert sich a ußerdem aus de $m$ Rücken marks-

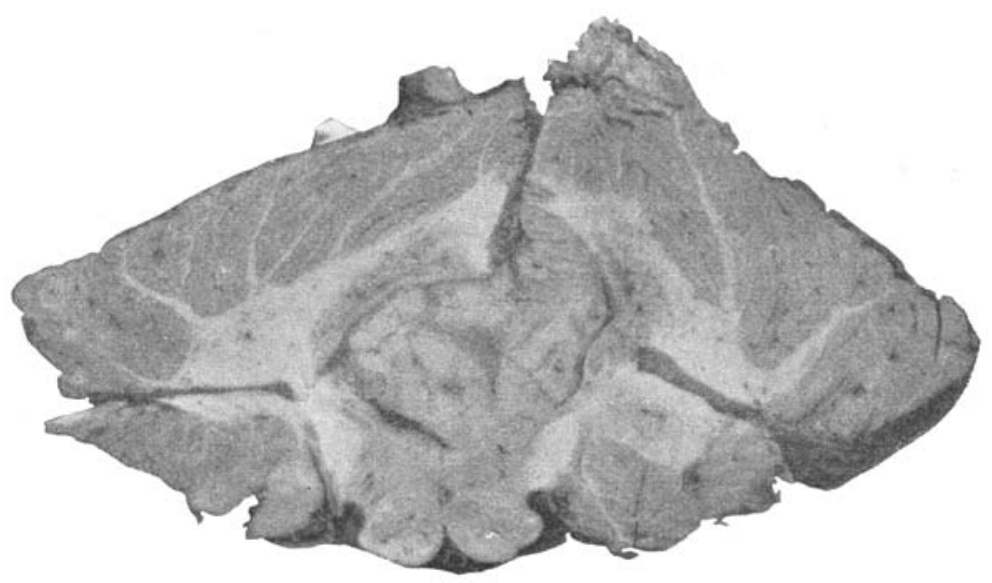

Fig. 5. Rundzellensarkom des vierten Ventrikels, vom Wurm ausgehend.

kanal. Die rechte Punktionsöffnung mündet in den Sinustransversus, durchdringt denselben jedoch nicht. Dagegen geht die linke Punktionsstelle durch den Sinus nahe an dessen unterem Rande hindurch. Die hintere Schädelgrube ist auffallend flach und schmal, so daß der Sinus dem Hinterhauptsloch erheblich näher liegt, als das normalerweise der Fall zu sein pflegt. Der Abstand des hinteren Randes des Foramen magnum vom Confluens sinuum beträgt $3,3 \mathrm{~cm}$.

Vom Wurm her ragt in den vierten Ventrikel hinein ein etwa walnußgroßer, weißlicher, derber Tumor, der nach unten auf die Medulla oblongata drückt und seitlich bis in die Flocculi des Kleinhirn hineingew uchert ist. (Rundzellensarkom.)

\section{Epikrise:}

Auch bei diesem Jungen mußte die sehr rasche Entwickelung allgemeiner Hirndruckerscheinungen im Verlaufe von etwa 6 Wochen, sowie der bei ihm beobachtete Anfall von plötzlichem Zusammenstürzen den Verdacht auf einen Tumor 
der hinteren Sehädelgrube und zwar cbenfalls wieder in der Nähe des vierten Ventrikels erwecken. Auch sämtliche Lokalsymptome, wie der, wenn auch nur gering ausgesprochene taumelnde Gang, die Hypotonie und Herabsetzung der Sehnenreflexe an den Beinen, dic abnorme Kopfhaltung, die halbscitige Gaumenparese, die Pulsirregularität und das Doppeltsehen infolge von rechtsseitiger Abducensund Trochlearisparese stimmten mit dieser Lokalisation gut überein. $D a$ die Wassermann-Reaktion des Blutes einmal schwach positiv ausgetallen war und auch Drisensehwellungen am Halse bestander, kam die Möglichkeit einer luetisehen Affektion sehr in Frage.

Zunächst wurde eine Ventrikelpunktion am rechten Seitenventrikel gemacht, wobei in $3 \mathrm{~cm}$ Hirntiefe etwa $30 \mathrm{~cm}$ klare Ventrikelflïssigkeit, aspiricrt wurde. Es geschah dies einerseits aus therapeutischen Rücksichten, da die Stauungspapille sehr rapide zugenommen hatte und Gefahr baldiger Erblindung vorlag, andererseits aus diagnostischem Interesse insofern, als wegen des Verdachtes anf eine luetische Affektion eine Untersuchang des Liquors cerebrospinalis dringend indiziert war, eine Spinalpunktion aber bei dem Verdacht auf einen Tumor der hinteren Schädelgrube in Anbetracht der bekannten fruheren sehlechten Erfahrungen nicht gewagt, werden konnte. Die Liquoruntersuchung ergab keine Lymphocytose und negativen Ausfall der Phase I und Wassermannschent Reaktion. Auch eime nochmalige Serumuntersuchung nach Wassermann fiel negativ aus. Fin luetischer Prozeß im Gohim war demnach ausgeschlossen. An den folgenden zwei Tagen war das subjektive Befinden des Kranken wesentlich besser und die Doppelbilder verschwunden. Auch objekiiv konnte ein Zurückgehen der Stauungspapille festgestellt werden und die Augenmuskellähmung war nitht mehr nachzuweiscn.

Drei Tage nach der Ventrikelpunktion wurden zwei Kleinhirnpunktionen an den typisohen Punkten am Kleinhirn und zwar, wie ich das stets tue, noch etwas unterhalb der Mitte der Verbindungsstelle zwischen Protuberantia oceip. externa und der Spitze des Processus mastoideus vorgenommen. Bei der linksseitigen Punktion wurde normales Kleinhirn ohne Blutbeimengung gewonnen. Bei der rechtsseitigen wurden sofort nach der vermeintlichen Durchstechung der Dura, also in etwa $1 / 4^{-1 / 2} \mathrm{~cm}$ Hirnticfe einige com dunkelroten Blates aspiriert, worauf die Kanüle sogleich wieder zurürkgezogen wurde. Die beiden Kleinhimpunktionen waren vormittags zwischen 10--11 Lhr vorgenommen worden. Do das Befinden des Kranken, abgesehen von Erbrechen nach dem Mittag- und Alvendessen keine auffällige Veränderung gegenüber dem Befund vor der Punktion zeigte, lag kein Anlab zu einem weiteren operativen Eingriff vor. $A \mathrm{~m}$ folgenden Morgen trat, nachdem der Junge während der Nacht mehrfach über Kopfschmerzen geklagt hatte, der Fxitus letalis ein.

Pei der Sektion fand sich ein walnußgroßer in den vierten Ventrikel hincinragender derber Tumor, der auf die Medulla oblongata drückte. Ferner war ein erheblicher Bluterguß in der hinteren Schädelgrube und im Rückenmarkskanal vorhanden, welcher, wie sich feststellen ließ, infolge einer Durchstechung des linken Sinus transwersus cingetreton war. Der Sinus war gerade an seinem unteren Rande getroffen und hatte bei der Durchstechung den Findruck derber Dura gomacht, ohne daB dabei auch nur ein Tropfen Blut aspiriert wurde. Offenbar hatten sich die äußere und innere Sinuswandung bei der Durchstechung so dicht aneinander gelegt, daB beide Wandungen gleichzeitig durehstochen wurden und daher kein Blut in die Kanüle gelangte. Am rechten Sinus transversus war an symmetrischer Stelle die äußere Wandung des Sinus durehbohrt. Da hier gleich beim Eindringen der Kanüle in den Sinus dunkelrotes Blut aspiriert und dit Punktionsnadel zurïkgezogen wurde, kam es von dieser Stelle aus zu einer einige 
Minuten dauernden Blutentleerung nach außen, dagegen zu keiner Blutung in die Schädelhöhle.

Tumoren von der hier vorliegenden Lokalisation führen zwar an und für sich schon fast regelmäßig zu ganz plötzlichen Todesfällen. Es kann jedoch nicht zweifelhaft sein, daß der Eintritt des, angesichts der Unmöglichkeit einer Radikaloperation der Geschwulst, allerdings unvermeidlichen Todes, durch die Blutung hervorgerufen bzw. beschleunigt wurde.

\section{Zusammenfassung.}

Wenn es auch bei keinem von den soeben erörterten fünf Fällen dieser Gruppe gelang, den Sitz der Geschwulst mittels der Hirnpunktion direkt nachzuweisen, so war bei denselben doch das negative Resultat der Punktion für die Diagnose von großem Wert, indem es zeigte, daß der pathologische Prozeß an einer für die Punktionsnadel nicht erreichbaren und daher auch für die operative Entfernung ungeeigneten Stelle saß.

Nur die multiplen Durasarkome bei dem dritten Fall hätten mittels Hirnpunktion nachgewiesen und wohl auch exstirpiert werden können. Gerade bei diesem Kranken wurde aber eine diagnostische Hirnpunktion gar nicht ausgeführt, sondern nur zur Verminderung der hochgradigen Hirndruckerscheinungen am Tage der Aufnahme vom rechten und, da hier kein Liquor gewonnen wurde, auch vom linken Stirnhirn aus eine Ventrikelpunktion vorgenommen. Leider hielt der Rückgang der allgemeinen Hirndrucksymptome, welcher hierdurch erzielt wurde, nur einen Tag an und der Kranke starb wenige Tage später, bevor noch die in Aussicht genommenen Kleinhirnpunktionen ausgeführt werden konnten.

Bei den vier übrigen Fällen war auf Grund des klinischen Befundes jedesmal die Diagnose eines Tumors der hinteren Schädelgrube bzw. des Kleinhirns gestellt worden. In einem Teil der Fälle waren schon klinisch gewisse Anhaltspunkte dafür vorhanden, daß die Geschwulst im Bereiche des vierten Ventrikels lokalisiert sei. In allen diesen Fällen wurde durch die Himpunktion der Nachweis erbracht, daß die Hemisphären des Kleinhirns frei von Tumoren waren und daß demnach eine Lokalisation der Geschwülste an inoperabler Stelle, sei es im Wurm oder im Bereiche des vierten Ventrikels anzunehmen sei. Diese Annahme fand in sämtlichen Fällen ihre Bestätigung durch die Sektion. In allen vier Fällen fand sich ein Tumor im vierten Ventrikel, welcher einmal von der Vierhügelregion her und dreimal vom Wurm her in denselben hineingewachsen war.

Der negative Ausfall der Hirnpunktion war somit in allen diesen Fällen insofern vom hohen diagnostischem Wert, als er zeigte, daß die auf Grund der klinischen Untersuchung angenommenen Tumoren des Kleinhirns nicht an operabeler Stelle in den Kleinhirnhemisphären, 
sondern im Bereiche des vierten Ventrikels bzw. im Wurm und in der Vierhügelregion, $d . h$. an inoperabler Stelle saßen.

Bei diesen Kranken kamen nun auch wieder eine Reihe von direkten Folgeerscheinungen der Hirnpunktion, teils günstiger, teils ungünstiger Art zur Beobachtung.

So zeigte Fall $3 \mathrm{im}$ Anschluß an eine Entleerung von $20 \mathrm{ccm}$ Liquor cerebrospinalis durch Ventrikelpunktion vorübergehend besseres Befinden. Dasselbe wurde bei dem fünften Fall nach Aspiration von $30 \mathrm{ccm}$ Ventrikelflüssigkeit beobachtet. Hierbei war nach zwei Tagen die Stauungspapille geringer, die vorher vorhandenen Doppelbilder verschwanden und die Augenmuskellähmung war nicht mehr nachweisbar.

Andererseits trat bei dem ersten Falle, einem Tumor im vierten Ventrikel, nach der Hirnpunktion ein eigentümlicher Krampfanfall, bestehend in drehenden und windenden Rumpfbewegungen und in Anziehen der Extremitäten an den Rumpf ein. Ob dieser Anfall, der etwa eine Stunde nach der Hirnpunktion auftrat, durch dieselbe verursacht war, dürfte schwer zu entscheiden sein. Irgendwelche weiteren Erscheinungen, die als Folge der Punktion hätten gedeutet werden können, kamen nicht zur Beobachtung. Auch wurden später bei der Autopsie keinerlei Anzeichen einer vorausgegangenen Blutung im Bereich des Punktionskanales festgestellt.

Bei dem vierten Fall erfolgte zwei Stunden nach der Kleinhirnpunktion ein Anfall von Puls- und Respirationsverlangsamung, Blässe und Benommenheit. Den ganzen Nachmittag über zeigte dann der Patient ein munteres, attentes Verhalten, lachte und nahm Nahrung zu sich. Am Abend erfolgte ein ähnlicher Anfall, wie der eben beschriebene, welcher den Exitus letalis zur Folge hatte. Da solche für Geschwülste im vierten Ventrikel charakteristische Anfälle bei dem Jungen auch an den der Hirnpunktion vorausgegangenen Tagen schon in der Klinik beobachtet worden waren, glaube ich nicht, daß man berechtigt ist, die nach der Hirnpunktion aufgetretenen Anfälle als eine direkte Folge der Hirnpunktion aufzufassen, wenn sich auch bei der Sektion ein minimales, etwa $1 \mathrm{~mm}$ dickes, subdurales Blutextravasat in der rechten hinteren Schädelgrube, das aus einer angestochenen oberflächlichen Kleinhirnvene stammte, vorfand.

Dagegen hat bei dem fünften Fall eine durch die Hirnpunktion verursachte Blutung den, mit Rücksicht auf die Lokalisation des inoperablen Tumors im vierten Ventrikel allerdings unvermeidlichen Exitus letalis bedingt. Der Bluterguß war hier durch eine Verletzung des Sinus transversus verursacht, welcher auf der linken Seite an seinem unteren Rande mit der Punktionsnadel durchstochen wurde. Der beim Durchstich durch den Sinus gefühlte abnorme Widerstand war als derbe 
verdickte Dura aufgefaßt worden. Blut floß dabei nach außen aus der Punktionsnadel nicht aus, weil eben nur der untere Rand des Sinus durchstochen war und die Nadel nicht eigentlich in den Hohlraum des Sinus gelangte. Bei der Punktion der rechten Seite dagegen drang die Nadel in das Lumen des Sinus transversus. Hier floß sofort Blut durch die Hohlnadel nach außen, worauf dieselbe wieder zurückgezogen wurde, ohne daß die Innenwand des Sinus verletzt war.

Die Punktion war bei diesen Kranken ebenso wie bei den zahlreichen anderen Patienten, bei welchen ich Kleinhirnpunktionen vorgenommen habe, unterhalb des von Neisser angegebenen Kleinhirnpunktes, d. h. unterhalb der Mitte der Verbindungslinie zwischen Protoberantia occipitalis externa und Spitze des Processus mastoideus ausgeführt worden. Obwohl Neisser diesen Punkt selbst als die geeignetste Stelle für Kleinhirnpunktionen erklärt hatte, bin ich doch sowohl bei allen Fällen dieser Gruppe als auch bei allen übrigen von mir ausgeführten Kleinhirnpunktionen stets aus Vorsicht noch etwa $1 / 2 \mathrm{~cm}$ unterhalb dieses Punktes eingegangen, um ja eine Verletzung des Sinus transversus zu vermeiden. In der Regel fand sich auch der Bohrkanal in der Hinterhauptsschuppe bei den Fällen, die zur Operation oder Sektion kamen, etwa $1 / 2-1 \mathrm{~cm}$ unterhalb des Sinus transversus. Daß in diesem Falle trotzdem eine Verletzung des Sinus stattfand, erklärte sich bei der Sektion daraus, daß die hintere Schädelgrube im Verhältnis zu den übrigen Schädelmaßen außerordentlich klein war. Die Entfernung vom hinteren Rande des Foramen occipitale bis zum unteren Rande des Sinus transversus betrug nur $3,3 \mathrm{~cm}$, bei einem Schädelumfang von 55 und einem Längebogen von $35 \mathrm{~cm}$. Daß nicht nur die Konfiguration des Schädels im allgemeinen sondern auch speziell die der hinteren Schädelgrube ein sehr variables Verhalten zeigen kann, ist ja bekannt. Der Fall lehrt also, daß es in gewissen Fällen mit schmaler hinterer Schädelgrube gefährlich sein kann, an den Neisserschen Kleinhirnpunkte einzugehen. Auch eine abnorme Kürze der Processus mastoidei könnte einmal die Ursache dafür abgeben, daß es bei der Punktion in der Mitte zwischen Protuberantia occipitalis externa und Spitze des Processus mastoideus zu einer Verletzung des Sinus transversus käme. Eine Röntgenaufnahme des Schädels könnte wohl, wie Anto $n^{1}$ ) betont, einen gewissen Aufschluß über den Umfang der hin teren Schädelgrube und über die Lage der Sinus transversi geben. Immerhin ist es fraglich, ob mit diesem Verfahren praktische Resultate für die Zwecke der Hirnpunktion gewonnen werden könnten, da die Maße sich je nach der Kopfhaltung bei der Röntgenaufnahme leicht verschieben.

1) Anton, Zur Diagnose und Behandlung der Geschwülste im 4. Ventrikel. Archiv f. Psych. 48, H. 2. 
Die Gefahr einer Sinusverletzung bei der Hirnpunktion ist bisher als nicht sehr erheblich angesehen worden. So berichtete Da nielse $\mathbf{n}^{1}$ ) über einen Fall, bei welchem der Sinus transversus durchstochen wurde, ohne daß eine Blutung erfolgte. Er nahm an, daß der starke Hirndruck in seinem Falle den Ausflu $\beta$ des Blutes aus dem Sinus verhindert habe. Der vorliegende Fall lehrt aber, daß dieser Annahme Danielsens jedenfalls keine Allgemeingültigkeit zukommt.

Nachdem es hier bei einer Punktion $1 / 2 \mathrm{~cm}$ unterhalb des Neisserschen Kleinhirnpunktes zu einer gefährlichen Sinusblutung gekommen ist, halte ich es für angezeigt, in künftigen Fällen von Kleinhirnpunktionen einen tiefer gelegenen Punkt als Bohrstelle zu wählen. Ich selbst werde in künftigen Fällen von Kleinhirnpunktionen jedenfalls mindestens $1 \mathrm{~cm}$ unterhalb der Mitte der Verbindungslinie zwischen Protuberantia occipitalis externa und Spitze des Processus mastoideus eingehen.

\section{Hirnpunktionen bei Fällen von Epilepsie.}

Außer den bisher erörterten Fällen, bei welchen es sich stets um Punktionen bei Hirntumoren mit nachfolgender Operation bzw. Sektion handelte, habe ich dann noch bei drei Patienten mit Epilepsie von Jacksonschen Charakter ohne allgemeine Hirndrucksymptome Hirnpunktionen ausgeführt. Einer derselben hatte früher einen Bandwurm beherbergt. Es lag daher die Möglichkeit vor, daß die epileptischen Anfälle durch Cysticerken ausgelöst waren. Bei den beiden anderen Kranken waren keinerlei Anhaltspunkte für die Pathogenese des Leidens vorhanden. Die Hirnpunktionen brachten bei diesen Fällen keine nähere Aufklärung bezüglich der Natur der Erkrankung. Nur konnte in einem der Fälle eine abnorme Beschaffenheit und erhebliche Verdickung des Schädels im Bereich der in Frage kommenden Hirnregion festgestellt werden. Die Gesamtdicke des Schädels betrug $1,25 \mathrm{~cm}$. Zwischen der oberflächlichen und tiefen kompakten Schicht bildete die Spongiosa einen deutlichen Hohlraum. Bei diesem Kranken ließen auch die Krampfanfälle nach dekompressiver Trepanation in der Gegend der motorischen Region wesentlich nach, während bei den beiden anderen durch die gleiche Operation kein nennenswerter Einfluß auf den Verlauf des Leidens festgestellt werden konnte. Immerhin haben diese Versuche gezeigt, daß man durch Gewinnung eines Urteils über die Dicke des Schädeldachs bei Epileptikern mittels der Hirnpunktion Fälle ausfindig machen kann, bei welchen die Anlegung einer Schädellücke einen günstigen Erfolg verspricht. Weitere Versuche nach dieser Richtung wären wünschenswert. Ein nachteiliger Einfluß der Hirnpunktion war bei keinem von diesen Fällen zu konstatieren.

1) Danielse n, l. c. 


\section{Hirnpunktionen bei Verdacht auf Hirntumor ohne nachfolgende Operation oder Sektion.}

Bei den bisher besprochenen Fällen handelte es sich stets um Kranke, bei welchen nach Vornahme der Hirnpunktion eine Operation bzw. Sektion stattfand, und bei welchen somit das durch die Hirnpunktion erzielte Resultat kontrolliert werden konnte.

Ich möchte nun noch wenigstens summarisch über eine Reihe von Himpunktionen berichten, bei welchen diese Kontrolle nicht möglich war. Die Punktionen hatten in allen diesen Fällen bis auf einen ein negatives Resultat.

Im ganzen handelte es sich hierbei um 18 Patienten. Neunmal kam dabei auf Grund der klinischen Untersuchung ein Tumor cer hinteren Schädelgrube und neunmal ein solcher des Großhirns in Frage. Bei den Kleinhirntumoren würden in der Regel zwei Kleinhirnpunktionen vorgenommen, eine an der linken, und eine an der rechten Hemisphäre. Auf Grund des negativen Resultats der Hirnpunktion wurde in diesen Fällen ein inoperabler Sitz der Geschwülste im Wurm bzw. etwas weiter frontal im Hirnstamm angenommen.

Bei den im Großhirn vermuteten Tumoren schwankte die klinische Lokaldiagnose in der Mehrzahl der Fälle zwischen dem rechten Stirnhirn und dem rechten Schläfelappen. Bei einigen von diesen Fällen wurde auf Grund des negativen Ausfalls der Hirnpunktionen auf einen inoperablen Sitz der Geschwulst ìm tiefen Marklager bzw. im Hirnstamm geschlossen. Nur bei einem von diesen Kranken wurde durch die Hirnpunktion ein positives Resultat erzielt. Hier war eine Geschwulst des linken Scheitellappens auf Grund der klinischen Untersuchung diagnostiziert. Die Hirnpunktion ergab am unteren und oberen Teil des linken Scheitellappens Zeichen der Erweichung, aber keinen Anhalt für das Bestehen eines Hirntumors. Der weitere Verlauf bestätigte denn auch dieses Resultat der Hirnpunktion, indem der Zustand sich während der folgenden Wochen so wesentlich besserte, dạ dèr Kranke etwa einen Monat nach der Hirnpunktion ohne nennenswerte Beschwerden entlassen werden konnte. Eine vor kurzem an die Ehefrau des Kranken gerichtete Anfrage über dessen Befinden ergab, daß, abgesehen von Vergeßlichkeit uñd Reizbarkejt, keine Störungen bei ihm wahrzunehmen seien.

Im übrigen ergaben die Anfragen bei den Angehörigen der nach Hause entlassenen Patienten, daß im ganzen sieben von diesen achtzehn Kranken seither gestorben sind. Eine Sektion hat leider nur bei einem dieser Fälle stattgefunden. Die klinische Diagnose hatte hierbei zwischen einem Tumor des rechten Stirnhirns und einem solchen des rechten Schläfenlappens geschwankt. Während seines etwa ein halbes Jahr dauernden Aufenthaltes in der Klinik hatte ich im ganzen bei ihm sechs 
Hirnpunktionen, vier am rechten Schläfenlappen und zwei am rechten Stirnhirn vorgenommen, die sämtlich ein negatives Resultat hatten. Bei der auswärts (Dr. Sch midt in Wittenberg) vorgenommenen Sektion fand sich überhaupt kein Tumor, sondern nur ein starker Hydrocephalus internus.

Unangenehme Nebenwirkungen der Hirnpunktionen sind bei keinem von diesen Fällen zur Beobachtung gekommen. Dagegen trat wieder einige Male eine vorübergehende Besserung der Hirndrucksymptome nach Ventrikelpunktion ein. So war in einem Fall nach Entleerung von $10 \mathrm{ccm}$ Ventrikelflüssigkeit das Sehvermögen besser, bei einem anderen verschwanden nach Aspiration von $25 \mathrm{ccm}$ Liquor die vorher sehr heftigen Kopfschmerzen.

\section{Schlußfolgerungen und kritisehe Bemerkungen.}

Die hier mitgeteilten weiteren Erfahrungen über Hirnpunktion haben zunächst wieder in einer Reihe von Fällen gezeigt, daß die Hirnpunktion ein vortreffliches diagnostisches Hilfsmittel zur Diagnose von Hirntumoren ist, das uns in vielen Fällen mit zweifelhafter klinischer Diagnose zu einem absolut sicheren Urteil über Sitz und Art der Hirngeschwülste verhelfen kann.

Im ganzen gelang unter diesen Fällen neunmal der Nachweis von verschiedenartig lokalisierten Hirntumoren mit Hilfe der Punktionsnadel, wobei die histologische Untersuchung ergab, daß es sich dreimal um Gliome, dreimal um Endotheliome, einmal um ein Carcinom, einmal um ein Melanom und einmal um ein Cholesteatom handelte. In einem zehnten Fall schließlich wurde aus dem Befund von atypisch gewucherten Gliafasern im Punktionspräparat der Schluß gezogen, daß eine reaktive Gliawucherung in der Umgebung einer tiefer liegenden Geschwulst vorliege.

Auch cystische Degeneration innerhalb eines Glioms und innerhalb eines Melanoms wurde mit Hilfe der Hirnpunktion festgestellt.

Alle diese Befunde wurden durch die nachfolgende Operation bzw. Sektion durchaus bestätigt.

Von großem Wert erwies sich auch bei einer Reihe von Fällen das negative Resultat der Punktion, d. h. der durch die Hirnpunktion in einem bestimmten Hirnteil nachgewiesene normale Hirnbefund.

In vier Fällen, in welchen klinisch die Diagnose eines Tumors der hinteren Schädelgrube gestellt war, ohne daß jedoch durch die klinische Untersuchung ein sicheres Urteil über den genaueren Sitz der Geschwülste innerhalb der hinteren Schädelgrube zu gewinnen war, wurde durch die Hirnpunktion jeweils ein normaler Befund an beiden Kleinhirnhemisphären erhoben. Hieraus wurde bei diesen vier Fällen geschlossen, daß inoperable Geschwülste im Wurm, in der Vierhügelgegend bzw. im 
Bereiche des vierten Ventrikels vorlagen. Auch bei allen diesen Fällen bestätigte die Sektion die auf Grund der Hirnpunktion gestellte Diagnose.

In einem Fall schließlich, in welchem sechs Hirnpunktionen normalen Befund ergeben hatten, fand sich bei der später auswärts vorgenommenen Sektion überhaupt kein Tumor, sondern nur ein Hydrocephalus internus.

In einer weiteren Reihe von Fällen, bei welchen freilich die Kontrolle durch die Operation bzw. Sektion fehlte, da die Kranken nicht in der Beobachtung der Klinik blieben, war der Sitz einer Geschwulst auf Grund des normalen Punktionsbefundes an verschiedenen Hirnteilen, an welchen er klinisch angenommen worden war, ausgeschlossen und dadurch ein zweckloser größerer operativer Eingriff vermieden worden. Die allgemeinen Hirndrucksymptome wurden bei einem Teil dieser Kranken erfolgreich durch Vornahme des Balkenstichs bekämpft ${ }^{1}$ ). Bei einem von diesen Patienten, bei welchem auf Grund der klinischen Untersuchung ein Tumor des linken Schläfen]appens angenommen worden war, ergab die Hirnpunktion Zeichen einer Erweichung und die im weiteren Verlauf eingetretene weitgehende Besserung des Zustandes wurde als eine Bestätigung dieser Diagnose aufgefaßt.

Daß den negativen Befunden der Hirnpunktion im Gegensatz zu der Behauptung Lewandowskys ${ }^{2}$ ) eine vollgültige diagnostische Bedeutung zukommt, beweisen besonders die vier Fälle von Tumoren der hinteren Schädelgrube mit Sektionsbefund, bei welchen auf Grund des Punktionsresultats ein Sitz der Geschwülste an operabler Stelle im Bereiche der Kleinhirnhemisphäre ausgeschlossen worden war. Utberhaupt hat sioh bisher unter den zahlreichen von mir punktierten Fällen bei der später vorgenommenen Operation oder Sektion niemals ein Tumor an einer Hirnregion vorgefunden, an welcher ein solcher auf Grund des Hirnpunktionsbefundes ausgeschlossen worden war.

Bernhardt und Borchardt ${ }^{3}$ ) führen einen Fall an, bei welchem mit der Punktionsnadel zweimal ein Tumor durchstochen wurde, ohne daß es gelang, Material aus demselben zu gewinnen und so die Diagnose zu sicherm. Allerdings war die Geschwulst mit einer mit Mandrin armierten Punktionsnadel durchstochen und nachher normales Gehirn aspiriert worden. Die hierbei geübte Art der Technik halte ich durchaus nicht für empfehlenswert. Bei Anwendung der von mir benützten Punktionsnadel und bei Befolgung des von mir vorgeschlagenen Vorgehens, wobei die Nadel zunächst mit dem Mandrin bis zur Hirnrinde eingeführt und dann nach Entfernung des Mandrins langsam von

1) Hierüber wird demnächst eingehend von Prof. Anton und Prof. v. Bra man $\mathbf{n}$ berichtet werden.

2) Lewandowsky, Zur Diagnose des Hirnabscesses. Med. Klin. 1908, Nr. 27.

3) Bernhardt und Borchardt, Zur Klinik der Stimhirntumoren nebst Bemerkungen über Hirnpunktion. Berl. klin. Wochenschr. 1909, Nr. 29. 
Zentimeter zu Zentimeter unter fortgesetztem Aspirieren bis zu etwa $3 \mathrm{~cm}$ Hirntiefe eingestochen und dann ebenfalls wieder unter beständigem Aspirieren langsam herausgezogen wird, halte ich einen derartigen Mißerfolg für vollständig ausgeschlossen.

Daß trotz der schönen und zahlreichen diagnostischen Erfolge mittels der Hirnpunktion doch eine verhältnismäßig große Zahl von Hirntumorverdächtigen die Klinik verließ, ohne daß eine sichere Lokaldiagnose mittels der Punktionsnadel gelungen und ohne daß ein operativer Eingriff zur Entfernung der Geschwulst gemacht worden war hatte verschiedenerlei Gründe. Bei den meisten von diesen Fällen hatte die Hirnpunktion an den Hirnteilen, an welchen auf Grund der klinischen Untersuchung der Sitz der Geschwulst vermutet worden war, ein negatives Resultat ergeben, $d$. h. es war bei der Punktion bis zu einer Hirntiefe von etwa $3 \mathrm{~cm}$ normale Hirnsubstanz aspiriert worden. Hieraus war zu schließen, daß der betreffende Hirnteil den Tumor überhaupt nicht, oder doch in solcher Tiefe beherbergte, daß eine Totalexstirpation als erfolglos zu betrachten war. Ein Teil von diesen Fällen mag auch zu der Gruppe der Pseudotumoren (Nonne) gehören, wie z. B. der eine Fall, bei welchem sechs Hirnpunktionen an stummen Hirnteilen normalen Hirnbefund ergeben hatten und bei welchem die später nach der Entlassung des Kranken auswärts vorgenommene Autopsie nur einen Hydrocephalus internus ergab.

Ein weiterer Grund dafür, daß es bei diesen Patienten nicht zur definitiven Diagnosestellung mittels der Hirnpunktion und zur operativen Entfernung der Geschwülste kam, lag darin, daß einige von diesen Kranken von dem behandelnden Arzte nur für wenige Tage zum Zwecke der Feststellung bzw. Ausschließung des Sitzes eines Tumors an einem bestimmten Hirnteil der Klinik überwiesen worden waren. Andere wurden aus irgendwelchen äußeren Gründen, z. B. wegen Ablaufs der Verpflichtung der Kasse zur Krankenfürsorge vor der definitiven Diagnosenstellung aus der Klinik abgeholt.

Immerhin aber halte ich es doch für möglich, daß bei einigen von diesen Fällen durch Vornahme zahlreicherer Hirnpunktionen namentlich an den sog. stummen Hirnteilen noch ein positives Resultat an operabler Stelle zu erzielen gewesen wäre.

Gewiß hat die Forderung ihre Berechtigung, daß die Hirnpunktion als eine mit gewissen Gefahren verbundene Operation nicht planlos ausgeführt werden darf. Schon in meiner ersten Publikation über Hirnpunktionen zur Diagnose von Hirntumoren ${ }^{1}$ ) habe ich ausdrücklich hervorgehoben, daß die Hirnpunktion sich stets auf eine sorgfältige neurologische Untersuchung und auf eine möglichst genaue klinische

1) Pfeifer, Ửber explorative Hirnpunktionen nach Schädelbohrung zur Diagnoce von Hirnturoren. Arch. f. Psych. u. Nervenkrankheiten 42, H. 2. 
Lokalisation des Tumors stützen müsse. Trotzdem meint Oppenhei ${ }^{\mathbf{1}}$ ), daß ich in der Indikationsstellung zur Vornahme von Hirnpunktionen bei meinen früher veröffentlichen Fällen zu weit gegangen sei. Wie mir scheint, ist dieser Vorwurf nicht berechtigt. Forster ${ }^{2}$ ), welcher die Indikationsstellung und Methodik der Hirnpunktion, wie sie an der Hallenser Nervenklinik geübt wird, aus eigener Erfahrung kennt, hat bereits betont, daß 0 p penheims Warnung für die von mir vorgenommenen Hirnpunktionen nicht zutreffe.

Meiner ersten Publikation über Hirnpunktionen bei Hirntumoren lagen 20 Fälle zugrunde, bei welchen 89 Punktionen ausgeführt waren, so daß also durchschnittlich nicht ganz 4,5 Punktionen auf einen $\mathrm{Pa}$ tienten kamen. Bei der vorliegenden Mitteilung handelt es sich um 91 Hirnpunktionen bei 36 Kranken, also durchschnittlich um etwa $21 / 2$ Punktionen bei dem einzelnen Fall. Aus den ausführlich mitgeteilten Krankengeschichten läßt sich bei vorurteilsloser Betrachtung ersehen, daß jede einzelne Punktion nach genauer klinischer Untersuchung und Beobachtung des Patienten wohl überlegt und begründet ist. Von einem planlosen Vorgehen kann da also keine Rede sein.

$\because$ Neisser und Pollack ${ }^{3}$ ) gehen in der Indikationsstellung für die Vornahme von Hirnpunktionen offenbar erheblich weiter als ich, wie man aus ihrer ersten Mitteilung ohne weiteres ersehen kann. Sie berichten da z. B. über einen Fall, bei dem 7 Punktionen in einer Sitzung gemacht wurden. In zwei weiteren Fällen wurden im ganzen allerdings in verschiedenen Sitzungen je 12 Hirnpunktionen ausgeführt. Wir machen hier in der Regel nicht mehr als eine oder zwei Hirnpunktionen in einer Sitzung. Unter den hier mitgeteilten Fällen wurde nur einmal eine größere Zahl von Punktionen, nämlich fünf bei Fall 5 der 2. Gruppe, in einer Sitzung ausgeführt. Hierbei lag aber der besondere Grund vor, daß der Patient in großer Entfernung auswärts wohnte, so daß die Punktionen nicht auf verschiedene Sitzungen verteilt werden konnten. Der Standpunkt von Neisser und Pollack kennzeichnet sich aus folgendem Satz ihrer Arbeit: „Wenn man überhaupt daran geht, durch Probepunktion einen Tumor zu suchen, darf man vor einem rücksichtslosen, systematischen, auf verschiedene Sitzungen zu verteilenden Durchpunktieren der betreffenden Schädelhälfte nicht zurückschrecken." In seiner letzten Publikation über Hirnpunktion äußert sich Neisser ${ }^{4}$ ) bezüglich der Diagnose von Hirnabscessen, daß er durch zu große

1) Oppenheim, Lehrbuch der Nervenkrankheiten, 5. Auflage. Berlin 1908.

2) Forster, 1. c.

3) Neisser und Pollack, Die Hirnpunktion. Probepunktion und Punktion des Gehirns durch den intakten Schädel. Mitt. a. d. Grenzgeb. d. Med. u. Chir. 13.

4) Neisser, Lumbalpunktion und Hirnpunktion. Handbuch der Neurologie von Lewandowsky. Berlin 1910. 
Zurückhaltung mehr Schaden gesehen habe, als durch zu rücksichtsloses Punktieren. Besonders bei Abscessen stelle ein „Verlorensuchen" mit der Punktionsnadel oft die einzige Möglichkeit dar, einen Erfolg zu erreichen.

Wenn man Neisser und Pollack auch hierin nicht ganz folgt und der Forderung Rechnung trägt, daß jede Hirnpunktion durch eingehende klinische Erwägungen geleitet und begründet sein sollte, so sollte man doch auch andererseits ängstliche Bedenken nicht zu sehr in den Vordergrund stellen. Ich habe, wie schon gesagt, den Eindruck, da $ß$ bei den hier mitgeteilten Fällen eher zu wenig als zu viel punktiert wurde, und daß bei häufigerer Anwendung der Punktionsnadel vielleicht doch noch in dem einen oder anderen Falle eine Lokaldiagnose möglich gewesen wäre.

Daß wirklich, wie Oppenhei m annimmt, mehrere Hirnpunktionen an und für sich ohne sonstige Komplikationen einen wesentlichen Nachteil bedingen können, daß tatsächlich ein an verschiedenen Stellen punktiertesGehirn als ein geschädigtes und in seiner Widerstandsfähigkeit herabgesetztes Organ zu betrachten ist, davon habe ich mich bei den zahlreichen, von mir punktierten Kranken nicht überzeugen können. Wie ich in einer großen Reihe von Fällen durch mikroskopische Untersuchung der Stichkanäle an Gehirnen von Kranken, die zu verschiedenen Zeiten nach Vornahme von Hirnpunktion ad exitum kamen, nachgewiesen habe, beschränkt sich die Degeneration im Gehirn auf die unmittelbare Umgebung des Punktionskanals und schon nach kurzer Zeit treten auch beim erwachsenen Menschen Regenerationserscheinungen auf. Die Stichkanäle werden zunächst durch ein Granulationsgewebe ausgefüllt, in welches sehr bald von der Umgebung her aus Wachstumskolben neugebildete Fibrillen hineinwachsen, die sich später nach Monaten sogar mit einer Markscheide umgeben ${ }^{1}$ ). Wenn nach Hirnpunktion erhebliche subjektive Beschwerden oder objektiv nachweisbare cerebrale Symptome auftraten, so war in den Fällen, welche später einer Kontrolle bei der Operation oder Sektion zugängig waren, in der Regel eine Komplikation in Gestalt einer größeren oder kleineren Hämorrhagie dafür verantwortlich zu machen.

Die von Krause ${ }^{2}$ ) hervorgehobene Gefahr der Verschleppung von Geschwulstteilchen kann meines Erachtens ebenfalls nicht ernstlich in Betracht kommen. Wird ein Tumor mit genügend weiter Punktionsnadel erreicht, so wird er auch diagnostiziert und kommt bei Lokalisation an operabler Stelle ganz oder teilweise zur Entfernung. Ein im Punktionskanal hängengebliebenes Geschwulstpartikelchen würde in diesem

1) Pfeifer, Über die traumatische Degeneration und Regeneration des Gehirns erwachsener Menschen. Journ. f. Psychol. u. Neurol. 12, H. 23, 1908.

2) Krause, Chirurgie des Gehirns und Rückenmarks. 1908, S. 149ff. 
Falle wohl stets mit entfernt. Bei inoperablem Sitze des Tumors würde aber ein verschlepptes Geschwulstteilchen erst recht keinen wesentlichen Schaden verursachen. Übrigens läßt sich eine Verschleppung von Geschwulstteilchen, wenn sowohl während des Einführens als während des Zurückziehens der Punktionsnadel beständig aspiriert wird, wohl sicher vermeiden.

Auch die Gefahr der Infektion von außen muß natürlich vermieden werden, während bei Aspiration von Eiteransammlung innerhalb der Schädelhöhle sofort die Operation angeschlossen werden müßte. Ich habe bei meinen Hirnpunktionen niemals eine Infektion erlebt.

Die einzige wirkliche Gefahr der Hirnpunktion bei Hirntumoren ist die der Blutung. Dabei fällt besonders ins Gewicht, daß auch geringe Blutergüsse durch Steigerung des an und für sich schon erhöhten Hirndrucks den Tod herbeiführen können, wie dies ein Fall aus meiner ersten Mitteilung, bei welchem eine Verletzung der Arteria corporis callosi stattfand, lehrte.

Arterielle Blutungen mit schweren Folgeerscheinungen sind inzwischen noch mehrfach beobachtet worden, z. B. von Krause') und Borchard t ${ }^{2}$ ). Auch in unserer Klinik ist noch ein weiterer derartiger, nicht von mir punktierter Fall zur Beobachtung gekommen, über den von anderer Seite berichtet werden wird. Unter den hier mitgeteilten Fällen ist eine arterielle Blutung nicht vorgekommen. Die größeren Hirnarterien lassen sich bei genügender Vorsicht und bei normalen topographischen Verhältnissen in der Regel vermeiden. Immerhin können auch aus kleineren Seitenästen gefährliche Blutungen erfolgen und die Lage der Gefäße kann gerade bei Hirntumoren erheblich verändert sein, wie dies bei der von mir beobachteten Blutung aus einer Arteria corporis callosi der Fall war.

Neisser hält die von mir benützte dickere abgestumpfte Punktionsnadel für gefährlicher als seine $1 \mathrm{~mm}$ dicke, spitze Nadel. Hierzu sei ausdrücklich bemerkt, daß die oben erwähnte einzige tödliche arterielle Blutung, die ich selbst bei eigener Vornahme der Punktion erlebte, bei einem meiner ersten Punktionsfälle stattfand, wobei ich noch die spitze und dünne Neissersche Stahlnadel anwandte. Eben diese Blutung war für mich die Veranlassung, abgestumpfte und dickere Nadeln zu benützen, mit welchen man meines Erachtens weniger leicht Gefahr läuft, ein Gefäß anzuspießen. Zu einem größeren Volumen der Nadel entschloß ich mich noch aus dem weiteren Grunde, weil die $1 \mathrm{~mm}$ dicke Kanüle nur sehr geringe Aussicht bot, aus soliden Hirntumoren genügend Material für eine sichere histologische Diagnose zu gewinnen. Auch Krause erlebte einmal eine heftige arterielle Blutung aus einem

1) Kra u se, Zur Frage der Hirnpunktion. Berl. klin. Wochenschr. 1907, Nr. 29.

2) Bernhardt und Borchardt, l. c. 
Ast der Arteria Fossae Sylvii, ebenfalls, wie er ausdrücklich hervorhebt, bei Benützung der Neisserschen Nadel. Demgegenüber sei auf unsere Beobachtung bei Fall 1 der ersten Gruppe hingewiesen, bei welchem die Gefäßenden des mehrere Tage vorher mit meiner abgestumpften Nadel durchtrennten hinteren Astes der Arteria meningea media retrahiert und thrombosiert waren, ohne aa $ß$ die geringste Blutung stattgefunden hatte.

Venöse Blutungen sind im allgemeinen als viel weniger gefährlich zu betrachten. Doch berichteten Dreyfuß und Gans $\mathbf{s}^{\mathbf{1}}$ ) im vorigen Jahr über einen Fall, bei welchem infolge von Durchstechung einer Vene eine subdurale, subpiale und intracerebrale Blutung erzeugt wurde, die den Kranken schwer geschädigt hätte, wenn er nicht an der ursprünglichen Erkrankung zugrunde gegangen wäre. Auch bei einem von den hier mitgeteilten Fällen wurde durch Verletzung einer oberflächlichen Kleinhirnvene ein allerdings minimales subdurales Blutextravasat erzeugt, das aber nach dem oben eingehend geschilderten Verlauf der Erkrankung kaum von ernsterer Bedeutung war.

Daß eine Verletzung der venösen Sinus lebensgefährliche Blutungen verursache, war von Danielse $\mathbf{n}^{2}$ ) in Abrede gestellt worden, welcher nach Durchstechung eines Sinus transversus mit der Punktionsnadel keine Blutung eintreten sah. Als Ursache für das Ausbleiben der Blutung sah er den gesteigerten Hirndruck an. Daß man aber hierauf im allgemeinen nicht rechnen kann, haben wir leider in einem unserer Fälle erlebt. Der Sinus transversus wurde hierbei an seinem unteren Rande verletzt, obwohl $1 / 2$ om unterhalb des Neisserschen Kleinhirnpunktes eingegangen worden war. Als Ursache hierfür wurde, wie oben eingehend erörtert wurde, eine abnorme Kleinheit der hinteren Schädelgrube ermittelt. Zur Vermeidung ähnlicher Ereignisse halte ich es für angezeigt, in Zukunft bei Kleinhirnpunktionen $\mathrm{l} \mathrm{cm}$ unterhalb der Mitte der Protuberantia occipitalis externa und der Spitze des Processus mastoideus einzugehen.

Die Gefahr einer Verletzung von Venen und Arterien durch Hirnpunktion, namentlich wenn letztere durch Tumoren in ihrer Lage verschoben sind, wird sich jedenfalls niemals ganz vermeiden lassen, und man wird daher bei der Vornahme von Hirnpunktionen stets mit einer gewissen Gefahr der Blutung zu rechnen haben. Immerhin ist aber die Zahl der bisher beobachteten Blutungen im Verhältnis zu der der Hirnpunktionen keine sehr erhebliche. Bei den vorliegenden Fällen haben wir unter 91 Punktionen keine arterielle und nur eine venöse und eine Sinusblutung feststellen können, wovon nur die letztere von lebensgefährlicher Wirkung war. Beide Patienten litten aber an in-

1) Dre y u B und Gans, Zur Frage der Hirnpunktion usw. Neurol. Centralbl. H. 15. 1911 .

2) Danielsen, 1. c. 
operablen Tumoren, die vom Wurm bzw. von der Vierhügelgegend aus in den vierten Ventrikel hineingewachsen waren, so daß also der Tod bei den beiden Kranken absolut unvermeidlich war und bei dem einen durch die Punktion nur beschleunigt wurde.

Wenn man bedenkt, daß jeder Hirntumorkranke, bei dem die Geschwulst nicht festgestellt und entfernt wird, mit Sicherheit dem Tod verfallen ist, und daß bei der häufigen Unklarheit der klinischen Lokaldiagnose die Hirnpunktion das einzige Hilfsmittel zur Feststellung einer Geschwulst bleibt, so wird man diese Operation trotz der zweifellos damit verbundenen Gefahren als berechtigt anerkennen müssen.

Dazu kommt nun noch, daß mit Hilfe der Hirnpunktion in gewissen Fällen nicht nur diagnostische, sondern auch direkt therapeutische Erfolge erzielt werden können. Hierbei handelt es sich im wesentlichen um die Entfernung von Flüssigkeiten. Zur Genüge bekannt sind ja die therapeutischen Erfolge bei Fällen von Hirncysten, von Meningitis serosa, von subduralen und epiduralen Hämatomen und selbst von intracerebralen Blutergüssen. Aber auch bei Hirntumoren kann, wenn sie im Inneren cystisch degeneriert sind, durch Entfernung der Cystenflüssigkeit und dadurch bedingte Verminderung des Hirndrucks wenigstens vorübergehend Linderung geschaffen werden, wie zwei von den hier mitgeteilten Fällen wiederum beweisen. Ebenso bekannt und durch einige von den hier mitgeteilten Fällen wieder bestätigt ist die zeitweise Besserung, die durch Ventrikelpunktionen bei Hirntumorkranken erzielt werden kann.

$\mathrm{Ob}$ als druckentlastende Operation überhaupt, in Fällen, wo die Radikaloperation eines Hirntumors nicht möglich ist, die Dekompressivtrepanation odęr der Balkenstich, die Ventrikeldrainage, die konsequente Ventrikelpunktion oder die Lumbalpunktion am besten zur Anwendung kommt, darauf möchte ich hier nur mit wenigen Worten eingehen, zumal diese Punkte erst vor kurzem von $\mathrm{An}$ to $\mathrm{n}^{1}$ ) und $\mathrm{Pa} \mathrm{yr}^{2}$ ) eingehend erörtert wurden.

Die Indikationsstellung für die zu ergreifende druckentlastende Methode wird in der Hauptsache davon abhängig sein, ob die Hirndruckerscheinungen durch den Tumor an und für sich bezw. durch Schwellung der Hirnmasse bedingt sind oder ob dafür außerdem noch ein komplizierender Hydrocephalus internus verantwortlich zu machen ist.

Im ersteren Falle wäre natürlich die dekompressive Trepanation am Platze, während im letzteren die auf eine Entleerung der Ventrikelflüssigkeit hinzielenden Maßnahmen in Frage kämen.

1) Anton, Indikationen und Erfolge der operativen Behandlung des Gehirndrucks. Deutsche med. Wochenschr. 1912, Nr. 6.

2) Payr, Über druckentlastende Eingriffe bei Hirndruck. Deutsche med. Wochenschr. 1912, Nr. 6. 
Der Nachweis, ob ein Hydrocephalus internus überhaupt vorhanden ist oder nicht, ließe sich durch Ventrikelpunktion erbringen. Die Ventrikelpunktion ist außerdem auch besonders angezeigt in Fällen, in welchen es sich nur um die Erzielung einer kurzdauernden Druckentlastung, wie z. B. um die Verminderung eines starken Hirndrucks als Voroperation vor der Radikaloperation eines Hirntumors handelt. So hat z. B. die Punktion des rechten Unterhorns bei dem 4. Fall der ersten Gruppe kurz vor der Vornahme der Radikaloperation eine wesentliche Verminderung des Hirndrucks bewirkt und dadurch ein zu starkes Hervorquellen des Gehirns nach Eröffnung des Schädels verhindert.

Ist das Vorhandensein eines Hydrocephalus internus durch die Ventrikelpunktion festgestellt, so kämen diejenigen Maßnahmen, welche eine möglichst ausgiebige und dauernde Entleerung desselben zu gewährleisten vermögen, in Frage.

Von diesen Methoden ist zunächst die Lumbalpunktion wegen der großen Gefahren, die sie erwiesenermaßen bei Fällen von Hirntumoren im Gefolge haben kann, abzulehnen.

Die konsequente Ventrikelpunktion steht hinter dem Balkenstich und der Ventrikeldrainage in bezug auf die Intensität und Dauer der Wirkung zurück und hat außerdem den Nachteil, daß zur Erzielung eines nachhaltigen Erfolges eine sehr häufige Wiederholung des Eingriffs erforderlich ist.

$\mathrm{Ob}$ die Ventrikeldrainage oder der Balkenstich vorzuziehen ist, dürfte wohl zurzeit noch nicht sicher feststehen. Die Entscheidung hierüber bleibt weiteren Erfahrungen vorbehalten. Jedenfalls scheint mir aber unter diesen beiden Operationsmethden der Balkenstich den Vorzug der größeren Einfachheit und geringeren Gefährlichkeit zu haben.

\section{Erklärung der Tafeln VII-IX.}

Tafel VII.

Fig. 1. Endotheliom. Hirnpunktionspräparat von Fall 3. Gruppe I.

Fig. 2. Großzelliges Endotheliom (Grenze des Tumors gegen das Gehirn) Hirnpunktionspräparat von Fall 5. Gruppe I.

Tafel XIII.

Fig. 1. Cholesteatoma. Hirnpunktionspräparat von Fall 4. Gruppe I.

Fig. 2. Carcinoma metastaticum. Hirnpunktionspräparat von Fall 1. Gruppe II.

\section{Tafel IX.}

Fig. 1. Gliom. Hirnpunktionspräparat von Fall 3. Gruppe II.

Fig. 2. Melanoma. Hirnpunktionspräparat von Fall 2. Gruppe II. 